\title{
1 Parametric analysis of a cross-flow membrane-based parallel-plate 2 liquid desiccant dehumidification system: numerical and experimental 3 data
}

Department of Architecture and Built Environment, the University of Nottingham, University Park, Nottingham, NG7 2RD, UK

\section{Abstract}

Operating parameters of a membrane-based parallel-plate liquid desiccant dehumidification system are investigated in this paper. The liquid desiccant and air are in a cross-flow arrangement, and separated by semi-permeable membranes to avoid carry-over problem. A numerical model is developed to simulate the system performance, and validated by experimental and analytical results. Impacts of main operating parameters on the system performance (i.e. sensible, latent and total effectiveness) are evaluated, which include dimensionless parameters (i.e. solution to air mass flow rate ratio $m^{*}$ and number of heat transfer units $N T U$ ), solution properties (i.e. concentration $C_{s o l}$ and temperature $T_{\text {sol }}$ ) and inlet air conditions (i.e. temperature $T_{\text {air, in }}$ and relative humidity $R H_{\text {air,in }}$ ). It is found that $m^{*}$ and $N T U$ are two of the most important parameters influencing the system effectiveness. Even though the system performance can be improved by $m^{*}$ and $N T U$, its increasing gradient is limited when $m^{*}$ and $N T U$ exceed 1 and 4 respectively. Decreasing solution temperature does not make a great improvement to the system performance, however, increasing solution concentration is a good approach to enhance the latent effectiveness without influencing the sensible effectiveness. The system shows the broad adaptability in various weather conditions, and has the ability to provide relative stable state supply air.

Keywords: liquid desiccant, membrane-based, dehumidification, numerical modelling

*Corresponding author. Tel: +44 1158466141.E-mail address: jie.zhu@nottingham.ac.uk. 


\begin{tabular}{|c|c|}
\hline$A$ & membrane surface area $\left(\mathrm{m}^{2}\right)$ \\
\hline$c_{p}$ & specific heat capacity $(\mathrm{J} / \mathrm{kgK})$ \\
\hline C & concentration $(\%)$ \\
\hline$C_{r}^{*}$ & thermal capacity ratio \\
\hline$d$ & width of the rectangular channel $(\mathrm{m})$ \\
\hline$D$ & diffusivity $\left(\mathrm{m}^{2} / \mathrm{s}\right)$ \\
\hline$h$ & convective heat transfer coefficient $\left(\mathrm{W} / \mathrm{m}^{2} \mathrm{~K}\right)$ \\
\hline$h_{f g}$ & condensation heat of water $(\mathrm{J} / \mathrm{kg})$ \\
\hline$h^{*}$ & operating factor \\
\hline$H$ & height of the dehumidifier unit (m) \\
\hline$k$ & thermal conductivity $(\mathrm{W} / \mathrm{m} \mathrm{K})$ \\
\hline$L$ & length of the dehumidifier unit (m) \\
\hline$m^{*}$ & solution to air mass flow rate ratio \\
\hline$\dot{m}$ & mass flow rate $(\mathrm{kg} / \mathrm{s})$ \\
\hline$N T U$ & number of heat transfer units \\
\hline$N T U_{m}$ & number of mass transfer units \\
\hline$P$ & atmospheric pressure $(\mathrm{pa})$ \\
\hline pe & Peclet number \\
\hline$P_{v}$ & equilibrium vapour pressure of desiccant solution (pa) \\
\hline$R e$ & Reynolds number \\
\hline$R H$ & relative humidity $(\%)$ \\
\hline$T$ & temperature $\left({ }^{\circ} \mathrm{C}\right)$ \\
\hline$U$ & overall heat transfer coefficient $\left(\mathrm{W} / \mathrm{m}^{2} \mathrm{~K}\right)$ \\
\hline$U_{m}$ & overall mass transfer coefficient $\left(\mathrm{kg} / \mathrm{m}^{2} \mathrm{~s}\right)$ \\
\hline$\dot{V}$ & volumetric flow rate (l/min) \\
\hline$W$ & humidity ratio (kg/kg dry air) \\
\hline$X$ & solution mass fraction \\
\hline
\end{tabular}

\section{Greeks}

$\varepsilon$

effectiveness

$\delta \quad$ thickness of membrane (m)

$\rho \quad$ density $\left(\mathrm{kg} / \mathrm{m}^{3}\right)$ 
Superscripts

dimensionless

$\begin{array}{ll}\text { Subscripts } & \\ \text { air } & \text { air flow } \\ \text { crit } & \text { critical value } \\ \text { desi } & \text { desiccant } \\ \text { exp } & \text { experimental } \\ \text { in } & \text { inlet } \\ \text { lat } & \text { latent } \\ \text { m } & \text { mass transfer } \\ \text { mem } & \text { membrane } \\ \text { num } & \text { numerical } \\ \text { out } & \text { outlet } \\ \text { sen } & \text { sensible } \\ \text { sol } & \text { solution flow } \\ \text { tol } & \text { total }\end{array}$

\section{Introduction}

The global energy consumption has increased significantly in past decades as a result of growing population and rapidly developing economy. Buildings contribute to a significant part of the global energy consumption. In particular, heating, ventilation and air-conditioning (HVAC) systems are responsible for around 50\% of the energy consumed in buildings [1]. In hot and humid regions, occupants would feel uncomfortable and mildew would grow on building interior walls without proper air dehumidification [2]. Thus the energy efficient air conditioning system is of vital importance with considerations of improving occupant thermal comfort and productivity. It has been shown that the building energy consumption could be decreased by $20-64 \%$ with efficient dehumidification technologies [3]. The traditional cooling coil system has several advantages for its ability to remove sensible heat load within a conditioned space effectively, good stability in performance, long life and a reasonable electrical coefficient of performance (COP) of between 2 and 4 . However it is inefficient in dealing with latent heat load $[4,5]$. In the conventional cooling coil system, air dehumidification is achieved simply by cooling the air below its dew point for condensation in order to reduce its moisture content. This results in wet cooling coil surfaces that may cause growths of mould and bacteria, and consequently leads to undesirable healthy issues and poor indoor air quality $[4,6]$. Furthermore, the air leaving the cooling coil is normally overcooled 
and needs to be re-heated to an appropriate supply temperature. Therefore, this combined process consumes a considerable amount of energy to cool (typically using a vapour compression system) and heat (using hot water or electricity) the supply air [7]. Drawbacks of the traditional cooling coil system can be avoided by using a liquid desiccant dehumidification system. In this system dehumidification is achieved by using liquid desiccant to absorb water vapour from moist air directly. The liquid desiccant system has some merits, for example, it is more energy efficient, healthy and environmentally friendly than the conventional system [810]. Furthermore, it has a better ability in handling latent heat load and removing pollutants with low temperature heat sources, such as solar thermal energy and waste heat $[4,11]$. The traditional liquid desiccant system uses packed beds in the dehumidifier and regenerator, where air and desiccant solution are in direct contact. In such a system small desiccant droplets are carried over by the supply air to the conditioned environment, which badly affects occupant health, building structure and furniture [2]. Furthermore, this system has potential drawback of large pressure drop when the air flows through packed beds, which increases the operating cost. Selectively permeable membrane has been used to replace packed beds as heat and mass transfer medium to overcome the desiccant droplet carryover problem. In the membrane-based liquid desiccant dehumidification system air and desiccant are separated by the membranes. Furthermore, other harmful gases are also prevented from permeating to supply air side through membranes.

Many researches on the membrane-based liquid desiccant dehumidification have been conducted. Mahmud et al. [3] tested a novel run-around membrane energy exchanger (RAMEE), which consists of two counter-cross-flow membrane energy exchangers. According to their results, during summer test conditions, the total effectiveness increases with desiccant flow rate, but decreases with air flow rate. By contrast, the total effectiveness changes little with air and desiccant flow rates under winter test conditions. Moghaddam et al. [12] experimentally and numerically evaluated the performance of liquid desiccant system. They focused on the effect of thermal capacity ratio $\left(\mathrm{Cr}^{*}\right)$ on the performance of a counter-flow liquid-to-air membrane energy exchanger (LAMEE), and found that numerical model agrees with experimental data for the latent and total effectiveness of the LAMEE, and all effectiveness increase with $\mathrm{Cr}^{*}$ under all test conditions. They [13] also investigated the influences of various heat and mass transfer direction and desiccant solution on the steady state performance of a small-scale counter-flow LAMEE, and their research results indicate that changing the solution concentration is one way to control the supply air outlet humidity ratio. Moghaddam [14] experimentally and numerically studied solution-side effectiveness for a membrane energy exchanger as dehumidifier and regenerator, and found that the difference between the air-side and solution-side latent effectiveness is negligible. Moghaddam et al. [15] further tested the performance of a small-scale single-panel LAMEE under different conditions (e.g. heating and 
humidifying, cooling and humidifying and cooling and dehumidifying), and discovered that the system effectiveness always increases with number of heat transfer units $(N T U)$ under all test conditions. Abdel-Salam et al. [16] numerically investigated the performance of a counter-flow membrane liquid desiccant air-conditioning system. They focused on the effects of different operating parameters on the system overall energy performance and revealed that the system COP at the design condition is 0.68 , while the sensible heat ratio (the ratio of the sensible to total energy removed from the supply air) is in the range of 0.3 to 0.5 under different climatic, operating and design conditions. Vali et al. [17] developed a numerical model to evaluate the performance of a counter-cross LAMEE by considering effect of the system design parameters, such as aspect ratio and entrance ratio. They found that the effectiveness is in the range between the effectiveness of pure counter-flow and pure cross-flow LAMEEs with the same membrane area, and the counter-cross-flow LAMEE would have the same performance as a counter-flow LAMEE when the membrane area of practical design is increased by $10 \%$. Huang et al. [18] numerically and experimentally assessed the performance of a quasi-counter flow parallel-plate membrane contractor, and observed that the cooling and dehumidification effectiveness are deteriorated significantly compared to a cross-flow one's. Huang et al. [19, 20] also investigated novel internally-cooled parallel-plate membrane contractors with cross-flow and quasi-counter flow configurations, and found that their effectiveness can be significantly improved compared to adiabatic one. Hollow fiber membrane contractor is another type and has attracted more attention recently. Performances of hollow fiber contractors with parallel and cross flow configurations have been studied in many papers [21-24]. Huang et al. [25, 26] conducted several researches into an elliptical hollow fiber membrane tube bank, which is a more normal case in reality, the local and average Nusselt and Sherwood numbers under the conjugate heat and mass transfer boundary condition are obtained. Applications of membrane-based liquid desiccant humidification in real industry have also been reported [27-29].

As discussed previously, many experimental studies have been carried out to investigate the performance of the membrane-based system [3, 12-15, 30]. A few studies evaluate the performance of liquid desiccant system numerically [12-17] by examining the effects of several operating and design parameters on the effectiveness of LAMEE or the overall energy performance. Several numerical investigations [18-20, 31, 32] used models that solve momentum equation and continuity equation to obtain velocity field, energy and mass equation to obtain concentration and temperature distributions. These studies focus on the basic heat and mass transfer of a parallel plate membrane-based contractor. However, limited researches have been carried out to evaluate the performance of a cross-flow membrane-based parallel plate liquid desiccant system numerically by considering comprehensive operating parameters. In this study, the conjugate heat and mass transfer in a cross-flow membrane-based parallel-plate liquid desiccant (using lithium chloride as desiccant) dehumidification system is investigated 
131 by numerical modelling, the influences of three groups of main parameters (i.e. dimensionless 132 parameters: $N T U$ and solution to air mass flow rate ratio $m^{*}$, solution properties: temperature $133 T_{\text {sol }}$ and concentration $C_{\text {sol }}$, and inlet air conditions: temperature $T_{\text {air, in }}$ and relative humidity $\left.134 R H_{\text {air,in }}\right)$ are assessed. Moreover, the interactions of different parameters on the system 135 performance are also investigated. This work provides a comprehensive parametric study on 136 the membrane-based liquid desiccant dehumidifier performance, which supplies valuable data

137 for the optimum design in the dehumidification and air-conditioning systems in practice.

\section{Numerical model}

\subsection{Governing equations}

141 The structure of the membrane-based parallel-plate dehumidifier is depicted in Fig. 1(a), and

142 its air and solution flows are in a cross-flow arrangement. The air and solution channels are

143 seperated by semi-permeable membranes, thus heat and vapour can be transferred through 144 membranes while the desiccant solution is prevented from going through them. The coordinate 145 system used in numerical modelling is given in Fig. 1(b). As can be seen, the air and solution flow in $\mathrm{x}$ and $\mathrm{y}$ directions respectively, while heat and mass are exchanged in $\mathrm{z}$ direction. One air channel and one neighbouring solution channle are selected as the calculating domain.

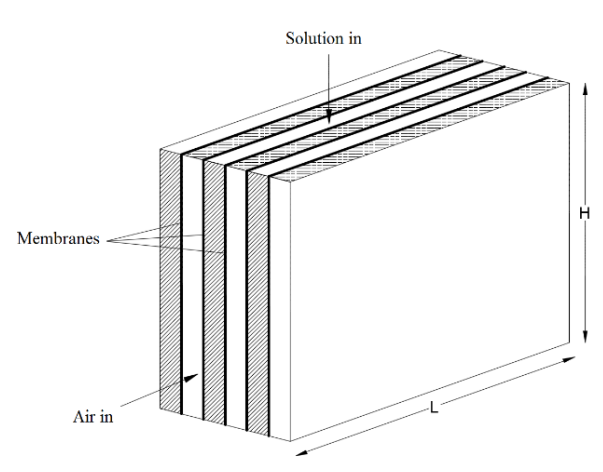

(a)

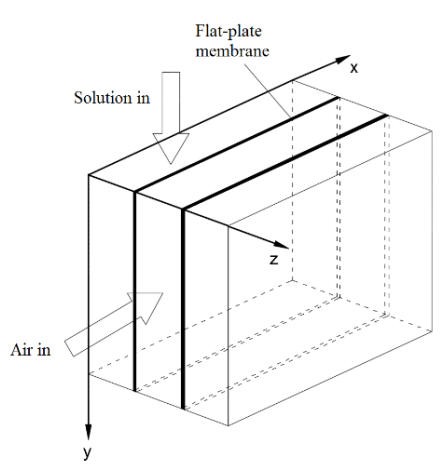

(b)

Fig. 1. Structure of membrane-based parallel-plate dehumidifier (a), and coordinate system used for numerical modelling (b).

Heat and mass transfer phenomena of the dehumidifier are complicated, many factors have the influences on heat and mass transfer characteristics, such as the fluid thermal properties, vapour condensation, fluid flow rate, etc. In order to develop the numerical model, the following assumptions for simplification in this study are made:

1) The dehumidifier is well-insulated, which means heat transfer between the dehumidifier and environment is not considered.

2) Heat and mass transfer through membrane is normal to the membrane in $\mathrm{z}$ direction. 
3) Axial conductions in both air and solution channels are neglected since Peclet numbers (pe) in the air and solution channels are much larger than $20[33,34]$.

4) Condensation heat is released to solution side only since the solution side mass transfer coefficient is much higher than that in the air side.

5) Both the air and solution flows are treated as laminar flows since their Reynolds numbers $(R e)$ are much lower than 2300 in most cases [12].

6) Both the air and solution flows are fully developed, while their temperature and concentration vary along channel length only.

\subsubsection{Solution side governing equations}

Heat and mass balance equations in the solution side are given as:

$\left(\frac{\dot{m}_{\text {sol }}}{L} \cdot \frac{\partial T_{\text {sol }}}{\partial y} \cdot C_{p, \text { sol }}\right) \cdot d x d y=\left[U\left(T_{\text {air }}-T_{\text {sol }}\right)+h_{f g} \cdot U_{m}\left(W_{\text {air }}-W_{\text {sol,mem }}\right)\right] d x d y$

$\frac{\dot{m}_{\text {desi }}}{L} \cdot \frac{\partial X_{\text {sol }}}{\partial y} \cdot d x d y=U_{m} \cdot\left(W_{\text {air }}-W_{\text {sol,men }}\right) d x d y$

Where in equations, $\dot{m}_{s o l}$ is solution mass flow rate $(\mathrm{kg} / \mathrm{s}) ; \dot{m}_{\text {desi }}$ is desiccant mass flow rate $(\mathrm{kg} / \mathrm{s}) ; L$ is the length of dehumidifier $(\mathrm{m})$ as illustrated in Fig. 1(a); $T_{\text {sol }}$ is solution temperature $\left({ }^{\circ} \mathrm{C}\right) ; T_{\text {air }}$ is air temperature $\left({ }^{\circ} \mathrm{C}\right) ; W_{\text {air }}$ is air humidity ratio $(\mathrm{kg} / \mathrm{kg}$ dry air $)$; $W_{\text {sol,men }}$ is humidity ratio of membrane surface on solution side $(\mathrm{kg} / \mathrm{kg}$ dry air $) ; X_{\text {sol }}$ is solution mass fraction, which is calculated as:

$$
X_{\text {sol }}=\frac{m_{\text {water }}}{m_{\text {desi }}}=\frac{1-C_{\text {sol }}}{C_{\text {sol }}}
$$

Where $C_{s o l}$ is solution mass concentration:

$$
C_{\text {sol }}=\frac{m_{\text {desi }}}{m_{\text {sol }}}
$$

$h_{f g}$ is water condensation heat $(\mathrm{J} / \mathrm{kg}) ; C_{p, s o l}$ is solution specific heat capacity $(\mathrm{J} / \mathrm{kgK})$; $U\left(W / m^{2} K\right)$ and $U_{m}\left(\mathrm{~kg} / \mathrm{m}^{2} \mathrm{~s}\right)$ are heat transfer and mass transfer coefficients respectively, which are given by:

$$
U=\left(\frac{1}{h_{\text {air }}}+\frac{\delta}{k_{\text {mem }}}+\frac{1}{h_{\text {sol }}}\right)^{-1}
$$

$U_{m}=\left(\frac{1}{h_{m, a i r}}+\frac{\delta}{k_{m, m e m}}\right)^{-1}$

Where $h_{\text {air }}$ and $h_{\text {sol }}$ are convective heat transfer coefficients in air and solution sides respectively $\left(\mathrm{W} / \mathrm{m}^{2} \mathrm{~K}\right) ; h_{m \text {,air }}$ is air side mass transfer coefficient $\left(\mathrm{kg} / \mathrm{m}^{2} \mathrm{~s}\right) ; \delta$ is membrane thickness $(m) ; k_{m e m}(W / m K)$ and $k_{m, m e m}(k g / m s)$ are membrane thermal conductivity and mass transfer conductivity respectively.

\subsubsection{Air side governing equations}

Similarly, heat and mass balance equations in the air side are given below:

$\frac{\dot{m}_{\text {air }}}{H} \cdot C_{p, \text { air }} \cdot \frac{\partial T_{\text {air }}}{\partial x}+U\left(T_{\text {air }}-T_{\text {sol }}\right)=0$ 
193

$\frac{\dot{m}_{\text {air }}}{H} \cdot \frac{\partial W_{\text {air }}}{\partial x} d x+U_{m}\left(W_{\text {air }}-W_{\text {sol,mem }}\right) d x d y=0$

194 Where $H$ is height of the dehumidifier $(m)$, as shown in Fig. $1(a) ; C_{p \text {,air }}$ is air specific heat capacity $(J / k g K)$.

196

$W^{*}=\frac{W-W_{\text {air, }, \text { in }}}{W_{0}}$

Where $W_{0}$ is equal to $\left(W_{\text {sol,in }}-W_{\text {air,in }}\right)$.

$214 m^{*}$ is mass flow rate ratio, which is defined by:

$215 m^{*}=\frac{\dot{m}_{\text {sol }}}{\dot{m}_{\text {air }}}$

$216 \mathrm{Cr}^{*}$ is thermal capacity ratio, which is defined by:

217

$$
C r^{*}=\frac{\left(\dot{m} c_{p}\right)_{\text {sol }}}{\left(\dot{m} c_{p}\right)_{\text {air }}}
$$

$218 h^{*}$ is operating factor, which is a dimensionless number defined by:

$219 \quad h^{*}=\frac{W_{0}}{T_{0}} \frac{h_{f g}}{c_{p, \text { air }}}$

$220 N T U$ and $N T U_{m}$ are numbers of heat and mass transfer respectively, which are defined by:

$221 \quad N T U=\frac{U A}{\left(\dot{m} c_{p}\right)_{\text {air }}}$

$222 N T U_{m}=\frac{U_{m} A}{\dot{m}_{\text {air }}}$ 
Where $A$ is total membrane area $\left(\mathrm{m}^{2}\right)$.

\subsection{Boundary conditions}

Boundary conditions for the solution side are:

$T_{\text {sol }}{ }^{*}=1$, at $y^{*}=0$

$228 \quad X_{\text {sol }}=X_{\text {sol,in }}$, at $y^{*}=0$

229 While the air side boundary conditions are:

$230 T_{\text {air }}{ }^{*}=0$, at $x^{*}=0$

$231 \quad W_{\text {air }}^{*}=0$, at $x^{*}=0$

\subsubsection{Heat transfer boundary conditions on membrane surfaces}

To solve the governing equations, heat and mass transfer boundary equations on membrane surfaces need to be established. Heat transfer boundary conditions are based on thermal energy

236 balance through the membrane:

$h_{\text {sol }}\left(T_{\text {sol,mem }}-T_{\text {sol }}\right)=U\left(T_{\text {air }}-T_{\text {sol,mem }}\right)+h_{f g} U_{m}\left(W_{\text {air }}-W_{\text {sol,mem }}\right)$

238 Eq. (26) can be normalized as:

$$
N T U_{\text {sol }}\left(T_{\text {sol,mem }}{ }^{*}-T_{\text {sol }}{ }^{*}\right)=\operatorname{NTU}\left(T_{\text {air }}{ }^{*}-T_{\text {sol,mem }}{ }^{*}\right)+N T U_{m} h^{*}\left(W_{\text {air }}{ }^{*}-W_{\text {sol,mem }}{ }^{*}\right)
$$

240 Where $N T U_{s o l}$ is number of heat transfer unit in solution side and defined by:

$241 \quad N T U_{\text {sol }}=\frac{h_{\text {sol }} A}{\left(\dot{m} c_{p}\right)_{\text {air }}}$

\subsubsection{Mass transfer boundary conditions on membrane surfaces}

244 Similarly, mass transfer boundary conditions are based on mass balance through the membrane:

$U_{m}\left(W_{\text {air }}-W_{\text {sol,mem }}\right)=h_{m, \text { sol }}\left(C_{\text {sol }}-C_{\text {sol,mem }}\right)$

246 Eq. (29) can be normalized as:

$N T U_{m} W_{0}\left(W_{\text {air }}{ }^{*}-W_{\text {sol,mem }}{ }^{*}\right)=N T U_{\text {m.sol }}\left(C_{\text {sol }}-C_{\text {sol,mem }}\right)$

248 Where $C_{\text {sol,mem }}$ is solution concentration in the interface between the solution and membrane

249 surface; $N T U_{m . s o l}$ is number of mass transfer unit in the solution side, which is defined by:

$250 \quad N T U_{m . s o l}=\frac{h_{m, \text { sol }} A}{\dot{m}_{\text {air }}}$

251 Where $\mathrm{h}_{m, \text { sol }}$ is solution side mass transfer coefficient $\left(\mathrm{kg} / \mathrm{m}^{2} \mathrm{~s}\right)$.

\subsection{Air and solution property equations}

254 In numerical modelling, the air specific humidity or humidity ratio $(\mathrm{kg} / \mathrm{kg}$ dry air $)$ is derived from its relative humidity by applying a correlation introduced in [35]. 
The solution equilibrium specific humidity $\left(W_{\text {sol }}\right)$ is used to calculate both the sensible and

257 latent effectiveness, the relationship between the specific humidity and vapour pressure is given 258 by [36]:

$W_{\text {sol }}=0.62198 \frac{P_{v}}{P-P_{v}}$

260 Where $P$ is atmospheric pressure $(P a)$ and $P_{v}$ is vapour pressure of desiccant solution $(P a)$.

The equilibrium vapour pressure of desiccant solution is a function of $T_{s o l}$ and $C_{s o l}\left(P_{v}=\right.$ $\left.f\left(T_{\text {sol }}, C_{\text {sol }}\right)\right)$, the correlation is given by [37]:

Where $P_{v}$ is solution equilibrium vapour pressure $(k P a), K$ is an electrolyte parameter relating to solute; $A, B, C, D$ and $E_{S}$ are parameters regarding to solvent. A psychrometric chart of $\mathrm{LiCl}$ solution is plotted and shown in Fig. 2.

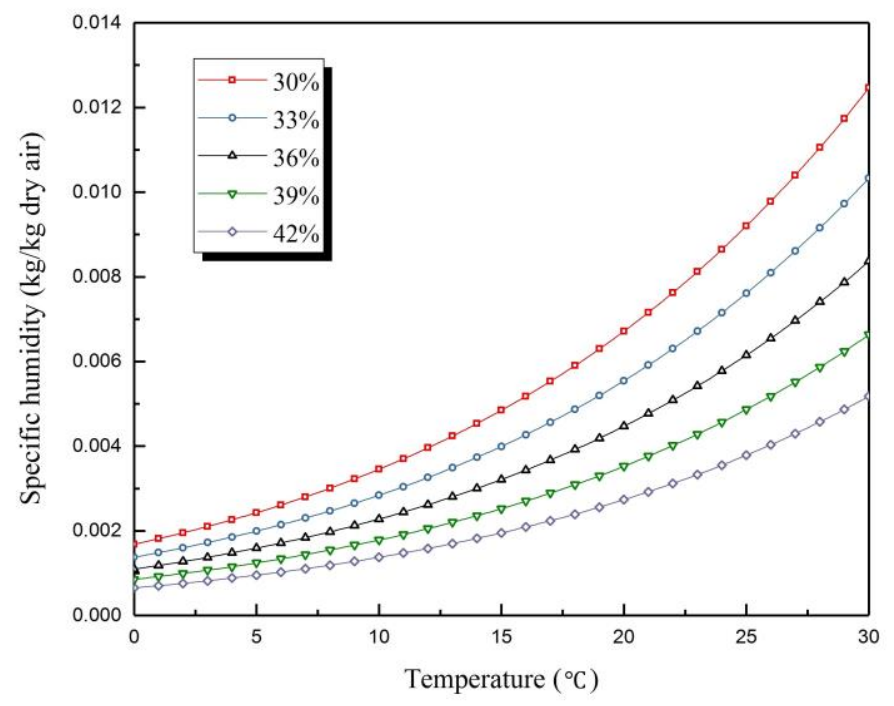

Fig. 2. Psychrometric chart of $\mathrm{LiCl}$.

\subsection{Performance evaluation}

Effectiveness is the most important parameter used to evaluate the performance of a heat and mass exchanger [38]. Three types of effectiveness have been defined in this study: sensible effectiveness $\left(\varepsilon_{s e n}\right)$, latent effectiveness $\left(\varepsilon_{\text {lat }}\right)$ and total effectiveness $\left(\varepsilon_{t o t}\right) . \varepsilon_{\text {sen }}$ is the ratio between the actual and maximum possible rates of sensible heat transfer in a heat exchanger. $\varepsilon_{\text {lat }}$ is the ratio between the actual and maximum possible moisture transfer rates in a mass exchanger. $\varepsilon_{t o t}$ is the ratio between the actual and maximum possible energy (enthalpy) transfer rates in a heat and mass exchanger. The capacity rate of desiccant solution is higher than that of the air, which means $C r^{*} \geq 1$, then the sensible, latent and total effectiveness are defined by Eqs. (34) - (36) [39]. 
284 Where $T_{\text {air,out }}$ is air temperature at the outlet $\left({ }^{\circ} \mathrm{C}\right)$ and $W_{\text {air,out }}$ is air humidity ratio at the 285 outlet $(\mathrm{kg} / \mathrm{kg}$ dry air $)$.

\section{Simulation procedure}

\subsection{Discretization of governing equations}

289 Governing equations in section 2.1 are solved by finite difference method, and discretized by a 290 forward difference scheme. Discretization equations are given below:

$291 T_{\text {sol }(m+1, n)}{ }^{*}-T_{\text {sol }(m, n)}{ }^{*}-d y^{*} N T U_{m} h^{*} C r\left[W_{\text {air }(m+1, n)^{*}}-W_{\text {sol,mem }(m+1, n)^{*}}\right]-$

$292 d y^{*} \operatorname{NTUCr}\left[T_{\text {air }(m+1, n)}{ }^{*}-T_{\text {sol }(m+1, n)}{ }^{*}\right]=0$

$293 X_{\text {sol }(m+1, n)}-X_{\text {sol }(m, n)}-d y^{*} m^{*} W_{0} N T U_{m}\left[1+X_{\text {sol }(m+1, n)}\right]\left[W_{\text {air }(m+1, n)}{ }^{*}-\right.$

$\left.\left.294 W_{\text {sol,mem }(m+1, n)}\right)^{*}\right]=0$

$295 T_{\text {air }(m, n+1)}{ }^{*}-T_{\text {air }(m, n)}{ }^{*}+d x^{*} N T U\left[T_{\text {air }(m, n+1)}{ }^{*}-W_{\text {sol }(m, n+1)}{ }^{*}=0\right.$

$296 W_{\text {air }(m, n+1)}{ }^{*}-W_{\text {air }(m, n)}{ }^{*}+d x^{*} N T U_{m}\left[W_{\text {air }(m, n+1)}{ }^{*}-W_{\text {sol,mem }(m, n+1)}{ }^{*}\right]=0$

297 Where $m$ is number of girds in $\mathrm{x}$ direction, and $n$ is number of girds in y direction.

298 Since the air and desiccant solution are closely interacted with each other, the governing 299 equations are solved in Matlab iteratively until converged. In order to guarantee the accuracy 300 of numerical results, numerical tests have been conducted to determine the grid size. It has been 301 found that $30 \times 60$ grids are adequate in this study, the result difference is less than $1.0 \%$ 302 compared with $50 \times 100$ grids. The numerical uncertainty is $1.0 \%$.

\subsection{Numerical solving scheme}

305 The numerical solution scheme used to solve interacted governing equations are given below:

1) Set the initial temperature and concentration fields for air and solution as boundary conditions.

2) Assume the initial humidity ratio on the membrane surface as the solution inlet equilibrium specific humidity.

3) Solve the energy equation (9) to get the solution temperature field $\left(T_{s o l}{ }^{*}\right)$.

4) Figure out the mass equation (10) to obtain the solution concentration field $\left(X_{\text {sol }}\right)$.

5) Deal with the energy equation (11) to acquire the air temperature field $\left(T_{\text {air }}{ }^{*}\right)$.

6) Solve the mass equation (12) to get the air humidity field $\left(W_{\text {air }}{ }^{*}\right)$. 
7) Based on the temperature and humidity fields for air and solution flows, solve heat and mass transfer boundary conditions on the membrane surface (26) and (27) to obtain the membrane surface temperature and concentration fields in the solution side $\left(T_{\text {sol,mem }}{ }^{*}\right.$ and $C_{\text {sol,mem }}$ ).

8) Calculate the membrane surface humidity field in the solution side $\left(W_{\text {sol,mem }}{ }^{*}\right)$ based on $T_{\text {sol,mem }}{ }^{*}$ and $C_{\text {sol,mem }}$.

9) Adopt new $W_{\text {sol,mem }}{ }^{*}$ as a default value and return to step 7 until $W_{\text {sol,mem }}{ }^{*}$ is converged.

10) Return to step 3 with the new $W_{\text {sol,mem }}{ }^{*}$ until $T_{\text {sol }}{ }^{*}, X_{\text {sol }}, T_{\text {air }}{ }^{*}$ and $W_{\text {air }}{ }^{*}$ are converged.

\section{Experimental work}

In order to assess the performance of a membrane-based parallel-plate liquid desiccant dehumidification system, a test facility is designed and built in the laboratory, which is depicted in Fig. 3.

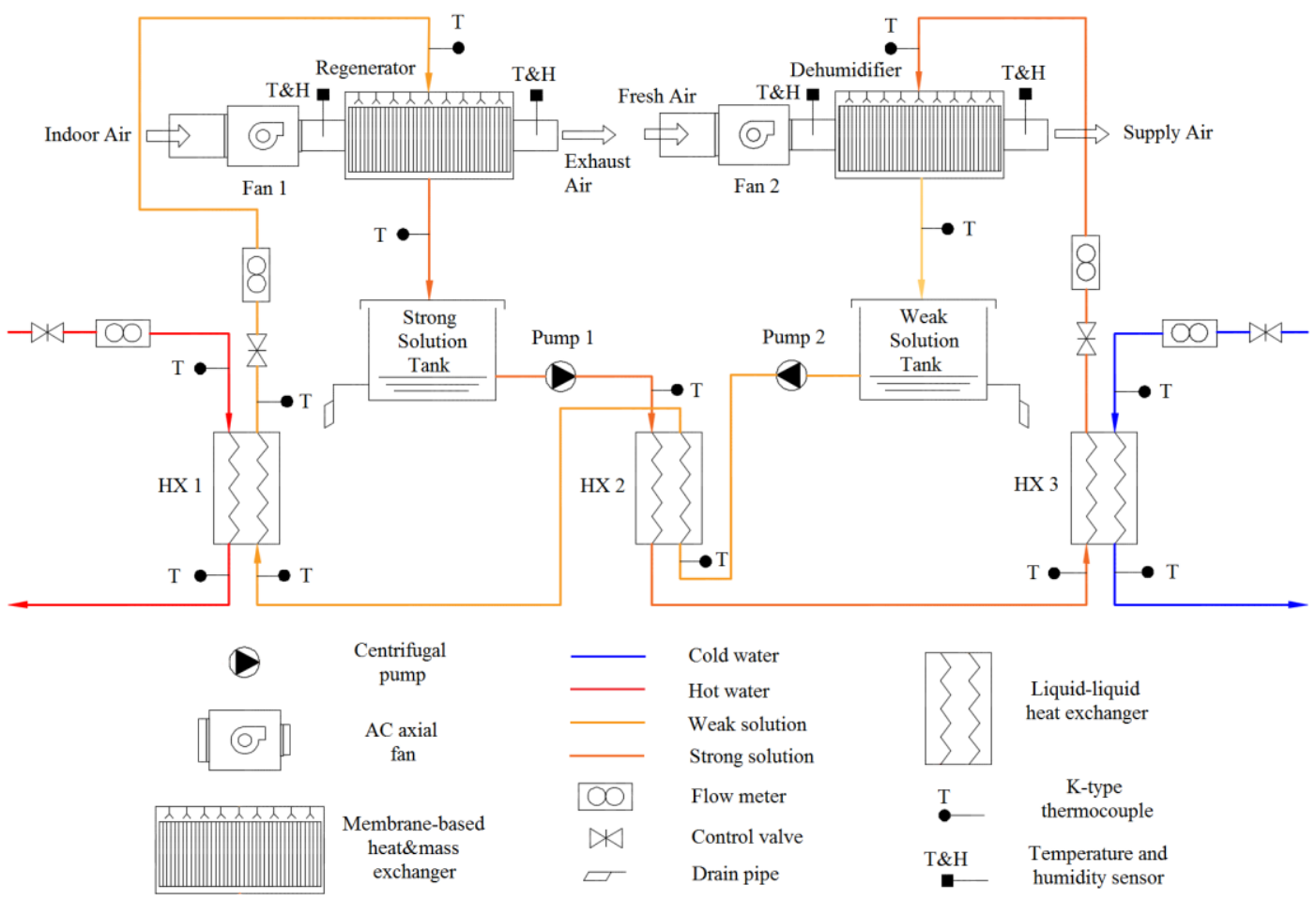

Fig. 3. Schematic diagram of the laboratory test rig.

The test rig mainly consists of a dehumidifier, a regenerator, two solution tanks and three heat exchange units. The outdoor air with high temperature and relative humidity is generated in the environmental chamber, and it flows into the dehumidifier where both its moisture content and 
temperature are reduced by cold desiccant solution, then it leaves the dehumidifier unit at a dry

336 and cool state. Its flow rate is controlled by adjusting an AC axial fan rotation speed (ebm-papst

337 Mulfingen GmbH \& Co. KG). The dehumidifier has a dimension of $410 \mathrm{~mm}(\mathrm{~L}) \times 230 \mathrm{~mm}(\mathrm{~W})$

$338 \times 210 \mathrm{~mm}(\mathrm{H})$ with 11 air channels and 11 solution channels. The regenerator has the same

339 structure as the dehumidifier. Three gauze layers are paved on the top surface of the

340 dehumidifier unit to ensure even solution distribution. The dehumidifier specifications and

341 membrane physical properties are given in Table 1.

\section{Table 1}

343 Dehumidifier specifications and membrane physical properties.

\begin{tabular}{ccc}
\hline Symbol & Unit & Value \\
\hline$L$ & $m$ & 0.41 \\
$W$ & $m$ & 0.23 \\
$H$ & $m$ & 0.21 \\
$d_{\text {air }}$ & $m$ & 0.0077 \\
$d_{\text {sol }}$ & $m$ & 0.0043 \\
$\delta_{\text {mem }}$ & $m$ & $0.5 \times 10^{-3}$ \\
$k_{\text {mem }}$ & $W / m K$ & 0.3 \\
$k_{m, \text { mem }}$ & $\mathrm{kg} / \mathrm{ms}$ & $3.87 \times 10^{-6}$ \\
\hline
\end{tabular}

344

345

346

347

348

349

350

Lithium chloride $(\mathrm{LiCl})$ is used as the desiccant in the system. The desiccant solution is circulated in the system by two identical pumps (15W centrifugal magnetically driven type with flow rate range of $0-10 \mathrm{~L} / \mathrm{min}$ ) and their flow rates are measured by two liquid flow indicators (Parker UCC PET 1-15 L/min). The desiccant solution and air transport properties are listed in Table 2.

\section{Table 2}

Air and desiccant solution transport properties.

\begin{tabular}{ccc}
\hline Symbol & Unit & Value \\
\hline$k_{\text {air }}$ & $\mathrm{W} / \mathrm{mK}$ & 0.03 \\
$k_{\text {sol }}$ & $W / \mathrm{mK}$ & 0.53 \\
$D_{\text {air }}$ & $\mathrm{m}^{2} / \mathrm{s}$ & $2.46 \times 10^{-5}$ \\
$D_{\text {sol }}$ & $\mathrm{m}^{2} / \mathrm{s}$ & $0.892 \times 10^{-2}$ \\
$c_{p, \text { air }}$ & $\mathrm{J} / \mathrm{kgK}$ & 1020 \\
$c_{p, \text { sol }}$ & $\mathrm{J} / \mathrm{kgK}$ & 3200 \\
$\rho_{\text {air }}$ & $\mathrm{kg} / \mathrm{m}^{3}$ & 1.29 \\
$\rho_{\text {sol }}$ & $\mathrm{kg} / \mathrm{m}^{3}$ & 1247 \\
\hline
\end{tabular}

Air velocities through the dehumidifier and regenerator are measured at the air duct outlets by a thermo-anemometer (Testo 405) with a measuring range up to $10 \mathrm{~m} / \mathrm{s}$. All fans at the inlets of the dehumidifier and regenerator are equipped with infinitely variable speed controllers to adjust air flow rates. All air inlets and outlets are instrumented with humidity and temperature sensors (Sensirion Evaluation KIT EK-H4). The desiccant solution and water temperatures are measured with K-type thermocouples, and all sensors are connected to a DT500 data logger. The dehumidifier, regenerator, heat exchangers, storage tanks and pipes are well insulated to 
reduce the environment influence. All measurement devices and their accuracies are listed in

361 Table 3. Uncertainty analysis has been conducted for all experimental data by applying a

362 method of propagation introduced by Taylor [40] to estimate uncertainties for experimental

363 data.

364 Table 3

365 Measurement devices and uncertainties.

\begin{tabular}{llll}
\hline Device & Measurement & Range & Uncertainty \\
\hline Testo thermos-anemometer & Air velocity & $0-10 \mathrm{~m} / \mathrm{s}$ & $\pm 5 \%$ \\
Sensiron Evaluation KIT EK-H4 & Temperature & $-40-125{ }^{\circ} \mathrm{C}$ & $\pm 0.4 \%$ \\
& Relative humidity & $0-100 \%$ & $\pm 3 \%$ \\
K-type thermocouple probe & Temperature & $0-1100^{\circ} \mathrm{C}$ & $\pm 0.75 \%$ \\
DT500 Datalogger & Data acquisition & - & $\pm 0.15 \%$ \\
Parker UCC PET liquid flow indicator & Solution flow rate & $1-15 \mathrm{~L} / \mathrm{min}$ & $\pm 5 \%$ \\
Parker liquid flow indicator & Water flow rate & $2-22 \mathrm{~L} / \mathrm{min}$ & $\pm 2 \%$ \\
\hline
\end{tabular}

\section{Results and discussion}

\subsection{Model validation}

Analytical solutions and experimental data are used to validate the numerical results. 12 groups of experimental data under different operating conditions are used to validate numerical results.

371 Under each operating condition, the numerical calculation and experimental results of sensible 372 effectiveness $\left(\varepsilon_{\text {sen }}\right)$ and latent effectiveness $\left(\varepsilon_{\text {lat }}\right)$ are compared, as shown in Table 4 . It can be seen that generally numerical modelling results of both $\varepsilon_{s e n}$ and $\varepsilon_{\text {lat }}$ agree well with experimental data. The maximum discrepancy between numerical results and experimental data for $\varepsilon_{s e n}$ is $8.756 \%$, while the maximum discrepancy for $\varepsilon_{\text {lat }}$ is $9.822 \%$.

Table 4

Comparisons between numerical results and experimental data.

\begin{tabular}{|l|l|l|l|l|l|l|l|l|l|}
\hline \multicolumn{2}{|l|}{ Operating conditions } & \multicolumn{2}{l|}{ Comparisons } \\
\hline NTU & $\mathrm{m}^{*}$ & $\begin{array}{l}\mathrm{m}_{\text {air }} \\
(\mathrm{kg} / \mathrm{s})\end{array}$ & $\begin{array}{l}\mathrm{m}_{\text {sol }} \\
(\mathrm{kg} / \mathrm{s})\end{array}$ & $\varepsilon_{\text {sen,num }}$ & $\varepsilon_{\text {sen,exp }}$ & $\begin{array}{l}\text { Error } \\
(\%)\end{array}$ & $\varepsilon_{\text {lat,num }}$ & $\varepsilon_{\text {lat,exp }}$ & $\begin{array}{l}\text { Error } \\
(\%)\end{array}$ \\
\hline 2 & 1 & 0.1216 & 0.1216 & 0.5699 & 0.520 & 8.756 & 0.5101 & 0.460 & 9.822 \\
\hline 2 & 2 & 0.1216 & 0.2431 & 0.7113 & 0.671 & 5.665 & 0.5311 & 0.500 & 5.856 \\
\hline 2 & 3 & 0.1216 & 0.3647 & 0.7608 & 0.708 & 6.940 & 0.5380 & 0.508 & 5.576 \\
\hline 2 & 4 & 0.1216 & 0.4862 & 0.7861 & 0.735 & 6.500 & 0.5413 & 0.511 & 5.597 \\
\hline 4 & 1 & 0.0608 & 0.0608 & 0.6276 & 0.576 & 8.221 & 0.7226 & 0.653 & 9.632 \\
\hline 4 & 2 & 0.0608 & 0.1216 & 0.8116 & 0.753 & 7.220 & 0.7632 & 0.742 & 2.778 \\
\hline 4 & 3 & 0.0608 & 0.1823 & 0.8704 & 0.810 & 6.940 & 0.7756 & 0.756 & 2.527 \\
\hline 4 & 4 & 0.0608 & 0.2432 & 0.8990 & 0.849 & 5.562 & 0.7816 & 0.750 & 4.043 \\
\hline 8 & 1 & 0.0304 & 0.0304 & 0.7376 & 0.686 & 6.996 & 0.8778 & 0.818 & 6.812 \\
\hline 8 & 2 & 0.0304 & 0.0608 & 0.9043 & 0.857 & 5.231 & 0.9270 & 0.916 & 1.187 \\
\hline 8 & 3 & 0.0304 & 0.0912 & 0.9440 & 0.894 & 5.297 & 0.9396 & 0.918 & 2.299 \\
\hline 8 & 4 & 0.0304 & 0.1216 & 0.9608 & 0.918 & 4.455 & 0.9452 & 0.928 & 1.820 \\
\hline
\end{tabular}




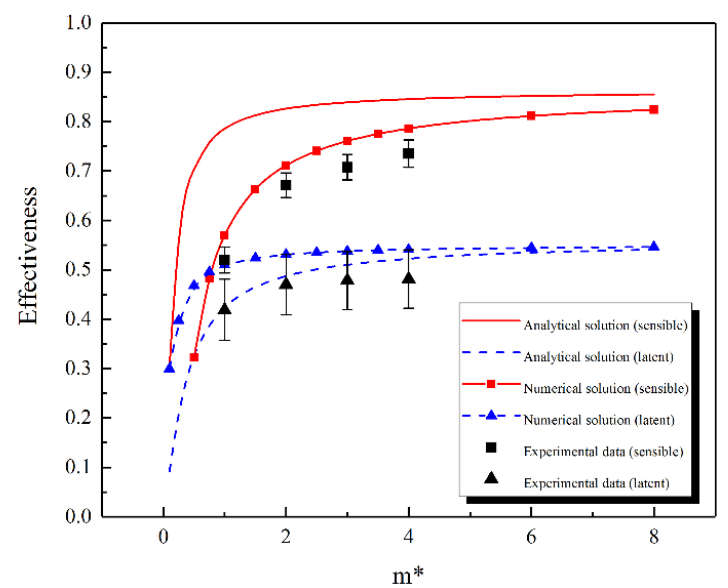

(a)

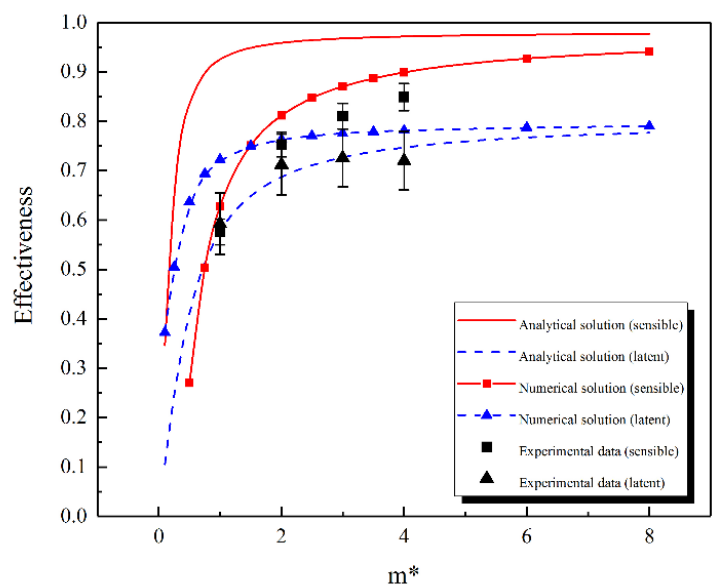

(b)

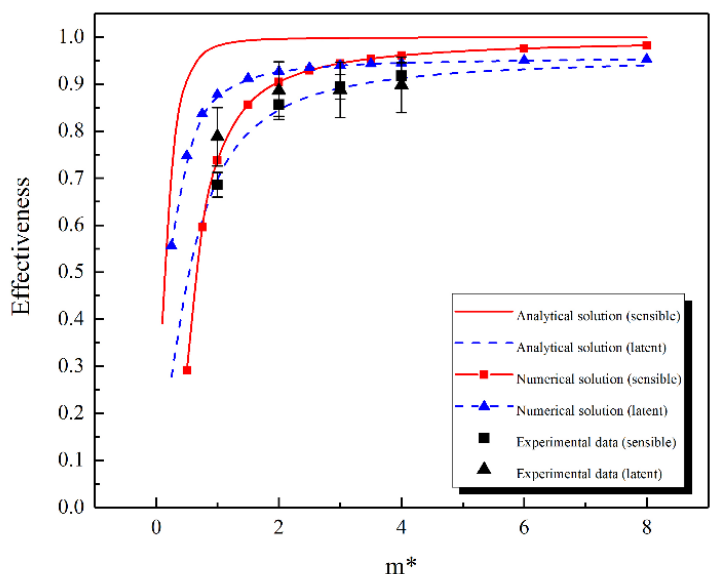

(c)

382 Fig. 4. Comparisons among numerical modelling, experimental data and analytical solutions for sensible and latent effectiveness under different NTU values: NTU=2(a); NTU=4(b);

$$
\mathrm{NTU}=8(\mathrm{c}) \text {. }
$$

The numerical modelling results and experimental data are presented in Fig. 4, the numerical modelling results follow the same trends of experimental data for both the sensible and latent effectiveness under different $N T U$ s. Based on the uncertainty analysis, which is shown as error 
bars for experimental data, it can be seen that numerical modelling results are within the tolerance range of experimental data. So it can be concluded that the agreements between the numerical modelling and experimental data for both the sensible and latent effectiveness are satisfied. It should be emphasized that under each $N T U$, the discrepancy reduces with the solution mass flow rate. This is because that the lower of solution mass flow rate, the greater influence of solution mal-distribution on the effectiveness. Analytical solutions to the model of an enthalpy exchanger with membrane core have been presented in several literatures. According to these literatures, the sensible effectiveness is a function of two dimensionless parameters $\left(N T U\right.$ and $\left.\mathrm{Cr}^{*}\right)$ for an unmixed cross flow, and given as $[41,42]$ :

$\varepsilon_{S}=1-\exp \left[\frac{\exp \left(-N T U^{0.78} C_{r}{ }^{*-1}\right)-1}{N T U^{-0.22} C_{r}{ }^{*-1}}\right]$

400 Similar to the sensible effectiveness, the latent effectiveness is calculated as [43]:

$401 \varepsilon_{l}=1-\exp \left\{\frac{N T U_{m}{ }^{0.22}}{m^{*-1}}\left[\exp \left(-m^{*-1} N T U_{m}{ }^{0.78}\right)-1\right]\right\}$

402 Results of the analytical solution are also given in Fig. 4. The numerical modelling and 403 analytical solution results have similar variation trends, an acceptable agreement between them 404 is achieved. Based on the comparisons, it is valid to predict the performance of the membranebased cross-flow dehumidifier by the numerical model.

406

\subsection{Temperature and humidity fields}

408 Temperature and humidity fields of the air and solution channels, and the membrane surface 409 are obtained based on the numerical model. The distributions of temperature and humidity ratio 410 in the air channel and membrane surface under $N T U=8$ and $m^{*}=2$ are plotted in Fig. 5. The 411 inlet temperatures of the air and solution are $30^{\circ} \mathrm{C}$ and $20^{\circ} \mathrm{C}$ respectively, while the inlet air 412 relative humidity and solution concentration are set as $70 \%$ and $39 \%$ respectively. It is observed 413 that the air has the lowest temperature $\left(20.00^{\circ} \mathrm{C}\right)$ and humidity ratio $(0.0042 \mathrm{~kg} / \mathrm{kg}$ dry air $)$ 414 at the right top corner of the air outlet. This is because the air at the top side of the dehumidifier 415 interacts with stronger and cooler desiccant solution. Furthermore, the air becomes cooler and 416 drier along the air channel length. It is noticed that the air temperature at left bottom corner of 417 the dehumidifier is slightly higher than its inlet temperature. This is owing to the increase of 418 the solution temperature during the dehumidification process. 


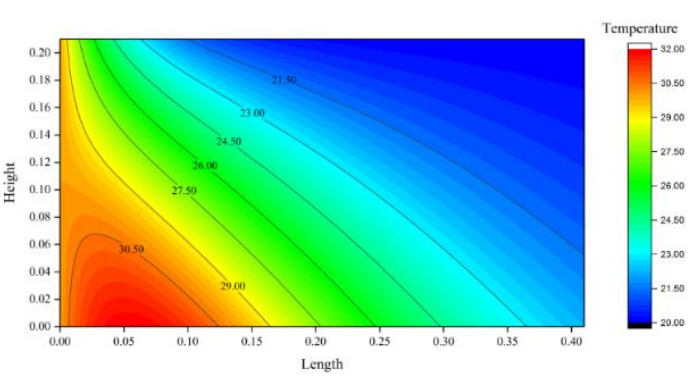

(a)

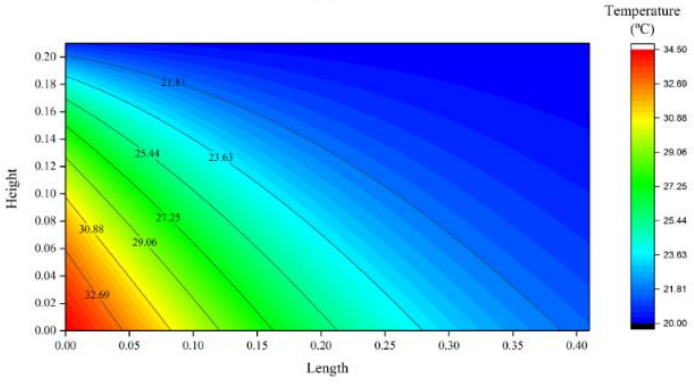

(c)

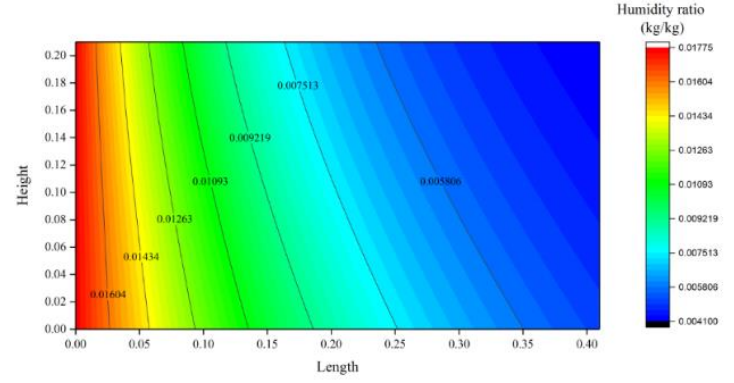

(b)

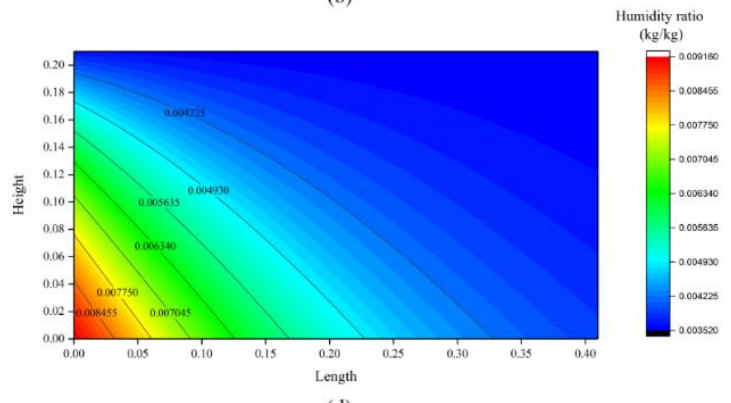

(d)

Fig. 5. Air temperature field (a); air humidity ratio field (b); temperature field on membrane surface (c); humidity ratio field on membrane surface (d).

Furthermore, Fig. 5 (c) and (d) reflect the temperature and humidity boundary conditions on the membrane surface, it is clear that the boundary condition is neither uniform temperature nor uniform humidity ratio. They are both non-uniform and two-dimensional profiles, the temperature and humidity ratio decrease along the diagonal line of the membrane surface.

\subsection{Effects of dimensionless parameters}

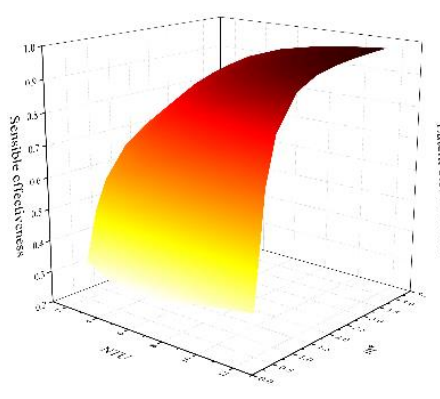

(a)

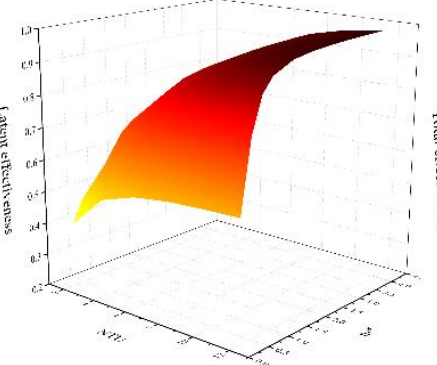

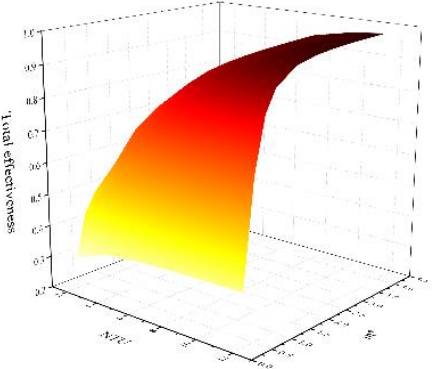

(c)

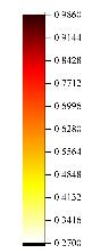

Fig. 6. Variations of effectiveness: (a) sensible effectiveness; (b) latent effectiveness; (c) total effectiveness with $m^{*}$ and $N T U$.

The variations of sensible, latent and total effectiveness with $m^{*}$ and NTU are given in Fig. 6. The maximum values of sensible, latent and total effectiveness are $0.9849,0.9845$ and 0.9846 respectively when $m^{*}=4$ and $N T U=12$. The minimum values of sensible, latent and total 
effectiveness are $0.3232,0.4682$ and 0.4353 when $m^{*}=0.5$ and $N T U=2$. Separate effects of $438 \quad m^{*}$ and $N T U$ are discussed then.

$439 \mathrm{~m}^{*}$ is the relative mass flow rate of two fluids in the dehumidifier, and changed by adjusting 440 solution mass flow rate while keeping air mass flow rate under each $N T U$. The variations of 441 sensible, latent and total effectiveness with $m^{*}$ at different NTUs are depicted in Figs. 7-9.

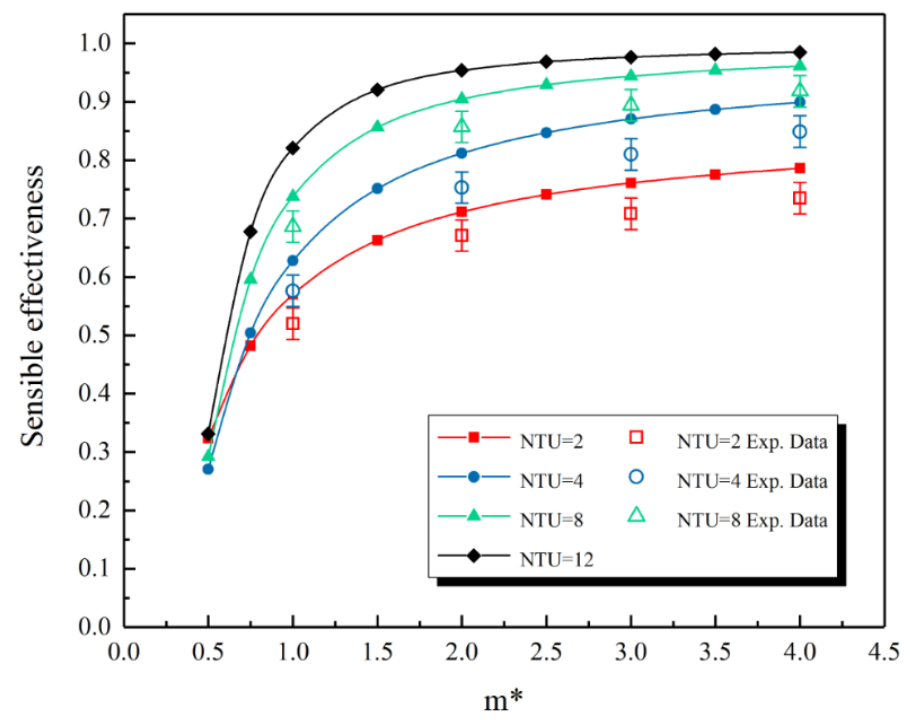

Fig. 7. Sensible effectiveness variations with $m^{*}$ under different $N T U$ s.

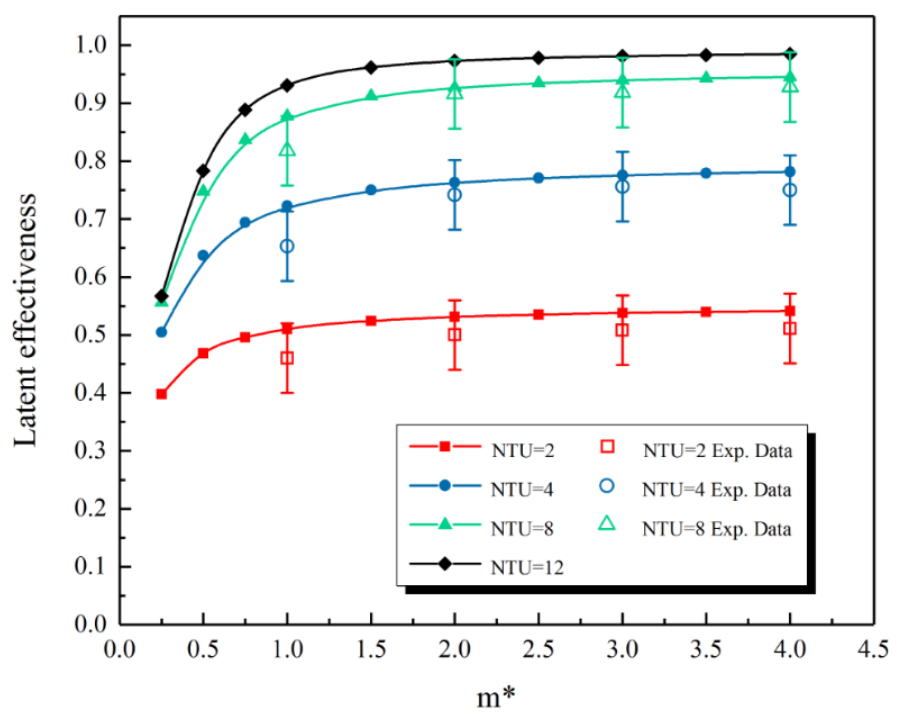

Fig. 8. Latent effectiveness variations with $m^{*}$ under different $N T U$ s. 


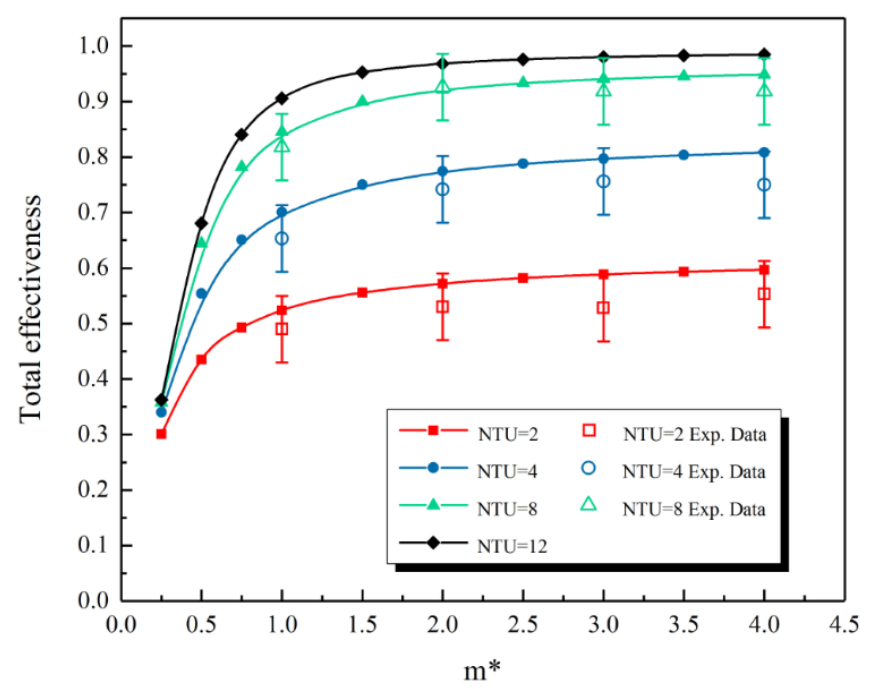

448

451 It is evident that $m^{*}$ has significant influences on sensible, latent and total effectiveness, which 452 all increase with $m^{*}$. The gradient of change for the sensible effectiveness is more considerable 453 than that for latent and total effectiveness. For instance, at $N T U=8$, the sensible effectiveness 454 rises from 0.2917 to 0.9608 as $m^{*}$ increases from 0.5 to 4 . In the meanwhile, the latent and total 455

Fig. 9. Total effectiveness variations with $m^{*}$ under different $N T U$ s. effectiveness vary from 0.7476 to 0.9452 and from 0.6441 to 0.9487 respectively. However, the gradients of their changes become moderate gradually and only a slight variation is observed once $m^{*}$ exceeds 1 . Take the latent effectiveness as an example, under $N T U=4$, the effectiveness increases by $43.15 \%$ as $m^{*}$ rises from 0.25 to 1.0 , while the effectiveness only increases by $8.16 \%$ when $m^{*}$ rises from 1.0 to 4.0 . Therefore a critical value of $m^{*}$ can be defined as $m_{c r i t}^{*}$, and the effectiveness are more sensitive to $m^{*}$ when $m^{*}$ is lower than $m_{c r i t}^{*}$. Once $m^{*}$ exceeds $m_{c r i t}^{*}$, there is not much significant change any more. Similar trends can be found in literatures [43, 44], in which their results show that both sensible and latent effectiveness increase with $m^{*}$ when $m^{*}<1$, and they are nearly constant when $m^{*} \geq 1$. Similar to $\mathrm{m}_{\text {crit }}^{*}$, another important indicator $\mathrm{Cr}_{\text {crit }}^{*}$ has been introduced in literatures $[45,46]$, as all effectiveness increase with $\mathrm{Cr}^{*}$ and are more sensitive before $\mathrm{Cr}^{*}$ reaching a critical value. This is easily explainable since $C r^{*}$ is proportional to $m^{*}$. Compared to $C r^{*}, m^{*}$ is a more straightforward parameter for the system. As a result, it is desirable to maintain the dehumidification system operating at a condition where $m^{*}$ is close to $m_{c r i t}^{*}$. It is also worth mentioning that the gradient of change with $m^{*}$ gets smoothly at low NTU. This is more obvious for the latent and total effectiveness. For example, the latent effectiveness increases by $36.21 \%$ (i.e. from 0.3974 to 0.5413 ) when $m^{*}$ varies from 0.25 to 4 under $N T U=2$, while under $N T U=12$, an growth of $73.63 \%$ (i.e. from 0.5670 to 0.9845 ) is observed for the same 
$m^{*}$ range. This means there is hardly benefit by increasing $m^{*}$ at low $N T U$ to improve the system performance.

On the other hand, NTU is another important dimensionless parameter affecting the effectiveness. In literature [46], NTU is treated as the most important parameter with the most significant impact on the dehumidification system. Compared to the flow rate, the nondimensional group NTU is a comprehensive indicating parameter because it eliminates the impact of channel geometric properties. In numerical modelling, NTU is changed by adjusting air mass flow rate, while the solution mass flow rate is changed proportionally to maintain a constant $m^{*}$ accordingly. Variations of effectiveness with $N T U$ under $m^{*}=4$ are shown in Fig. 10.

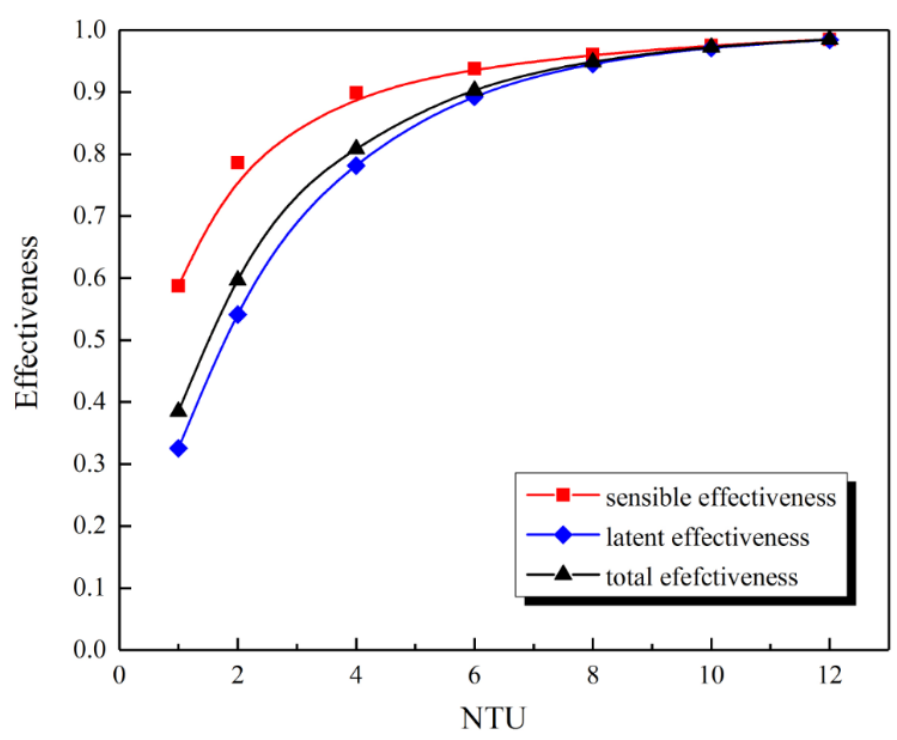

Fig. 10. Variations of effectiveness with $N T U$ under $m^{*}=4$.

All effectiveness are seriously affected by $N T U$ as indicated in Fig. 10. Under the same $m^{*}$, the sensible effectiveness is the highest while the latent effectiveness is the lowest among the three effectiveness. Similar to the influences of $m^{*}$, the three effectiveness vary more remarkably when $N T U$ is in the range of 1 to 4 . Once $N T U$ exceeds 4 , variations of these effectiveness tend to level off. For instance, under $m^{*}=4$, the sensible effectiveness increases by $53.02 \%$ (i.e. from 0.5875 to 0.899 ) when $N T U$ changes from 1 to 4 , conversely it only increases by $9.56 \%$ (i.e. from 0.899 to 0.9849 ) when $N T U$ varies from 4 to 14 . Cases are similar for the latent and total effectiveness. Thus similar to $m_{c r i t}^{*}$ or $C r_{c r i t}^{*}$, a critical value of $N T U$ exists and is defined as $N T U_{\text {crit }}$. Increasing $N T U$ beyond $N T U_{\text {crit }}$ would not enhance the system efficiency. Furthermore, it is observed from Figs. 7-9 that when $m^{*}$ is low, there is hardly benefit to improve these effectiveness by increasing $N T U$. This is more obvious for the sensible effectiveness. For instance, under $m^{*}=0.5$, increasing $N T U$ from 2 to 12 will only slightly 
enhance the sensible effectiveness from 0.3232 to 0.3311 . However, under $m^{*}=4$, the sensible

500 effectiveness improves from 0.7861 to 0.9849 when $N T U$ increases from 2 to 12 . Therefore

501 there is hardly significance to increase $N T U$ at low $m^{*}$ for performance improvement.

502 To sum up, these effectiveness increase with $m^{*}$ and $N T U$, but their increase gradients are 503 limited as $m^{*}>m_{\text {crit }}^{*}$ (i.e. 1 in this study) and $N T U>N T U_{\text {crit }}$ (i.e. 4 in this case). Effects of

$504 \mathrm{~m}^{*}$ and $N T U$ are interacted on each other. Under a relatively low NTU there is hardly benefit 505 to increase $m^{*}$, especially for the latent effectiveness. By contrast, with low $m^{*}$, no obvious 506 performance improvement could be achieved by increasing NTU, especially for the sensible 507 effectiveness.

\subsection{Effects of solution properties}

510 Solution temperature $\left(T_{\text {sol }}\right)$ and concentration $\left(C_{s o l}\right)$ affect the system performance, variations of sensible, latent and total effectiveness with $T_{\text {sol }}$ and $C_{\text {sol }}$ are presented in Fig. 11, while NTU and $m^{*}$ are set as 8 and 2 respectively.

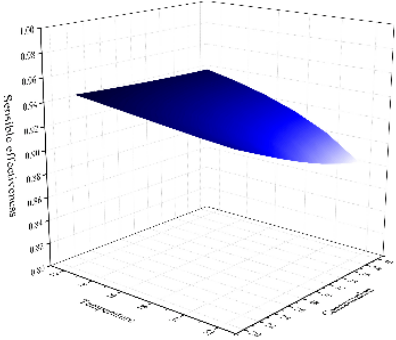

(a)

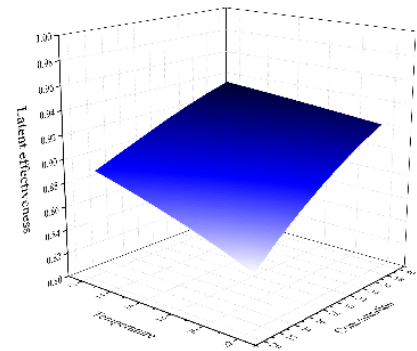

(b)

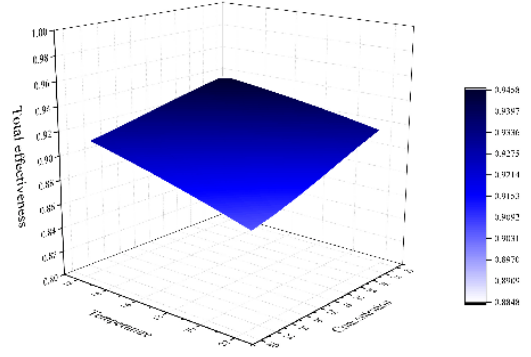

(c)

Fig. 11. Variations of effectiveness: (a) sensible effectiveness; (b) latent effectiveness; (c) total effectiveness with $T_{s o l}$ and $C_{s o l}$.

The sensible effectiveness reaches the maximum value of 0.9458 when $T_{\text {sol }}=12^{\circ} \mathrm{C}$ and $C_{\text {sol }}=$ $21 \%$, while its minimum value is 0.8848 when $T_{\text {sol }}=22^{\circ} \mathrm{C}$ and $C_{\text {sol }}=39 \%$. The maximum latent effectiveness is 0.9366 when $T_{\text {sol }}=12^{\circ} \mathrm{C}$ and $C_{\text {sol }}=39 \%$, and its minimum value is 0.8449 when $T_{\text {sol }}=22^{\circ} \mathrm{C}$ and $C_{\text {sol }}=21 \%$. For the total effectiveness, it reaches the maximum value of 0.9380 when $T_{\text {sol }}=12^{\circ} \mathrm{C}$ and $C_{\text {sol }}=39 \%$, while the minimum value is 0.8757 when $T_{\text {sol }}=22^{\circ} \mathrm{C}$ and $C_{\text {sol }}=21 \%$. Effects of $T_{\text {sol }}$ and $C_{\text {sol }}$ on the system performance are discussed separately then.

Solution temperature has a great influence on the system performance since it is closely related to the solution surface vapour pressure. The variations of the effectiveness with $T_{\text {sol }}$ under different $C_{\text {sol }}$ are shown in Figs. 12-14. 


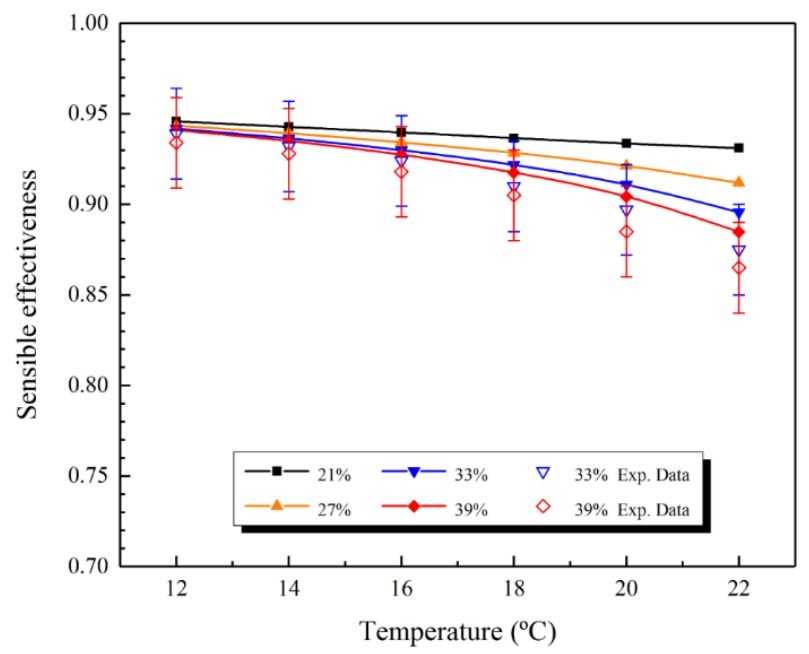

Fig. 12. Sensible effectiveness variations with $T_{\text {sol }}$ under different $C_{s o l}$.

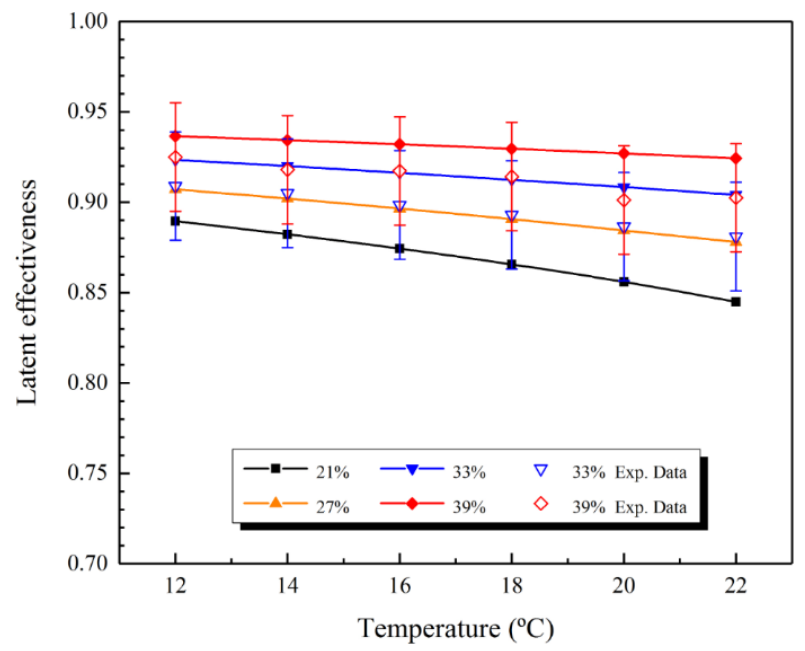

Fig. 13. Latent effectiveness variations with $T_{\text {sol }}$ under different $C_{\text {sol }}$.

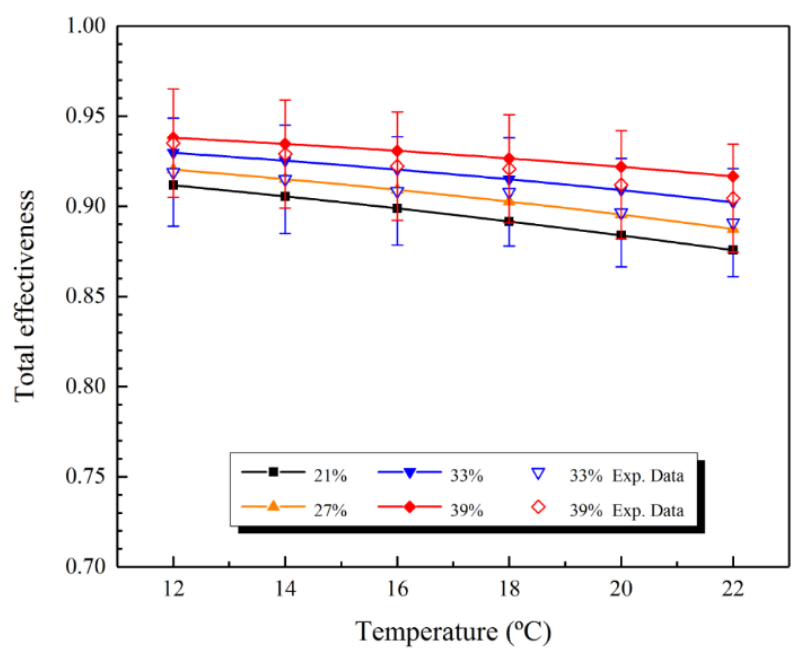

Fig. 14. Total effectiveness variations with $T_{\text {sol }}$ under different $C_{s o l}$. 
538 It is clearly reflected in Figs. 12-14 that all effectiveness decrease accordingly with the solution

539 temperature. The decrease of sensible effectiveness is easily understood since the increase of 540 solution temperature narrows the temperature difference between the solution and air. The 541 decrease of latent effectiveness is because vapour pressure in the solution side increases with 542 the solution temperature, which weakens the dehumidification potential. Although decreasing 543 the solution temperature can improve the sensible effectiveness, the improvement is not 544 significant. The sensible effectiveness is weakened by increasing dehumidification effect since 545 more latent heat released to the solution side would increase the solution temperature, which 546 would affect the sensible effectiveness negatively. It also should be mentioned that a low 547 solution concentration, the sensible effectiveness variation is almost negligible. For instance, 548 the sensible effectiveness increases by only $1.58 \%$ (i.e. from 0.9311 to 0.9458 ) when the 549 solution temperature decreases by $10^{\circ} \mathrm{C}$ under $C_{\text {sol }}=21 \%$. Thus when the solution 550 concentration is low, decreasing solution temperature will not improve the sensible 551 effectiveness significantly. The case is opposite for the latent effectiveness as it is more 552 sensitive to $T_{\text {sol }}$ when $C_{\text {sol }}$ is low. For example, under $C_{s o l}=21 \%$, the latent effectiveness 553 increases by $5.3 \%$ (i.e. from 0.8449 to 0.8896 ) when the solution temperature decreases from $55422^{\circ} \mathrm{C}$ to $12^{\circ} \mathrm{C}$. By contrast, it only increases by $1.33 \%$ (i.e. from 0.9243 to 0.9366 ) under $C_{\text {sol }}=$ $55539 \%$. This indicates that the latent effectiveness is more sensitive to solution temperature at a 556 low solution concentration. Nevertheless, the effect of $T_{\text {sol }}$ on the latent effectiveness is 557 insignificant compared to $C_{\text {sol }}$ as discussed subsequently.

558 Solution concentration affects the system performance as it is directly related to surface vapour 559 pressure. However, increasing $C_{\text {sol }}$ has different impacts on the sensible, latent and total 560 effectiveness, which can be observed from Fig. 15.

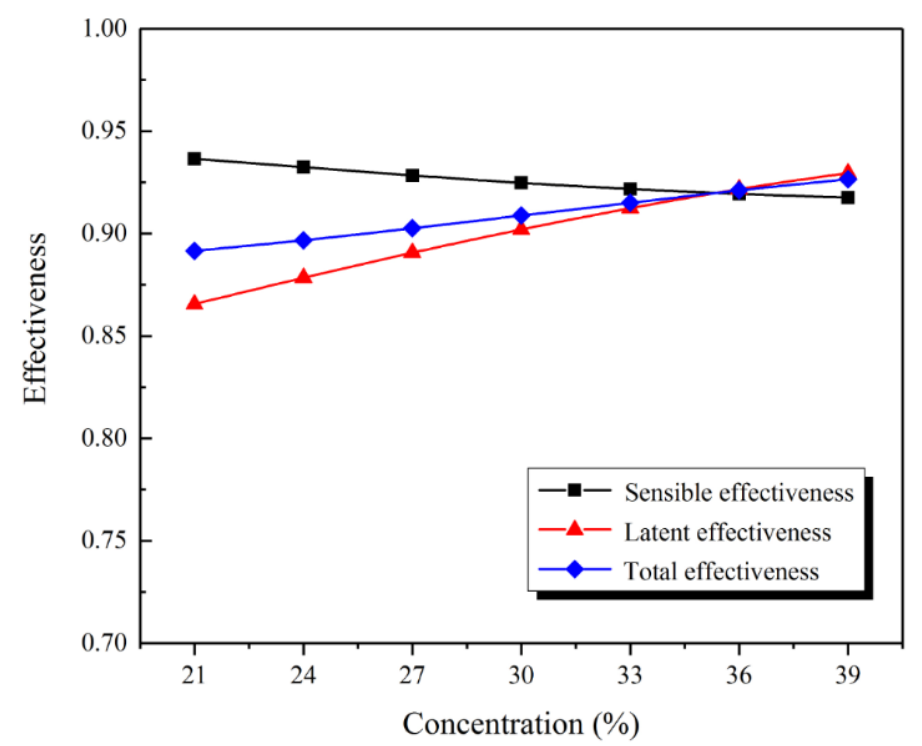

Fig. 15. Variations of effectiveness with $C_{\text {sol }}$ under $T_{\text {sol }}=18^{\circ} \mathrm{C}$. 
As presented in Fig. 15, increasing solution concentration from $21 \%$ to $39 \%$ would decrease 564 the sensible effectiveness from 0.9366 to 0.9176 , and increase the latent and total effectiveness from 0.8656 to 0.9296 and from 0.8916 to 0.9266 respectively. Similar to the effects of $T_{\text {sol }}$, increasing solution concentration will decrease the solution surface vapour pressure, thus the solution absorption ability will be enhanced and the latent effectiveness will be increased. The increased dehumidification ability will negatively affect the sensible effectiveness since more latent heat will be released to the solution side. The total effectiveness is mainly dominated by the latent effectiveness since they have the same variation trends. It can be observed in Fig. 12 that the sensible effectiveness is neither sensitive to $T_{s o l}$ nor $C_{\text {sol }}$. For the latent effectiveness, the effect of solution concentration is far more obvious than that on the sensible effectiveness. For instance, at $T_{\text {sol }}=12^{\circ} \mathrm{C}$, the sensible effectiveness decreases by $0.51 \%$ (i.e. from 0.9458 to 0.941 ) when $C_{\text {sol }}$ changes from $21 \%$ to $39 \%$, while the latent effectiveness increases by $5.28 \%$ (i.e. from 0.8896 to 0.9366 ). The latent effectiveness improvement is more significant at a higher solution temperature. For example, at $T_{\text {sol }}=22^{\circ} \mathrm{C}$, the latent effectiveness increases by $9.40 \%$ (i.e. from 0.8449 to 0.9243 ) when $C_{\text {sol }}$ varies from $21 \%$ to $39 \%$.

To sum up, the sensible effectiveness is insensitive to both $T_{\text {sol }}$ and $C_{\text {sol }}$, while the latent effectiveness is comparatively more sensitive. Thus in practical applications, a low solution temperature is not necessary since it is energy consuming and no significant performance improvement could be achieved. In the meanwhile, at a relatively high solution temperature, increasing $C_{s o l}$ will improve dehumidification ability more considerably. It implies that increasing solution concentration is a better approach to improve the latent effectiveness without decreasing the sensible effectiveness.

\subsection{Effects of inlet air condition}

Inlet air condition (i.e. temperature $T_{a i r, \text { in }}$ and relative humidity $R H_{\text {air, in }}$ ) is of vital importance to evaluate the adaptivity of the system. Variations of the sensible, latent and total effectiveness with $T_{\text {air,in }}$ and $R H_{\text {air,in }}$ are presented in Fig. 16, while $N T U$ and $m^{*}$ are set as 8 and 2 respectively.

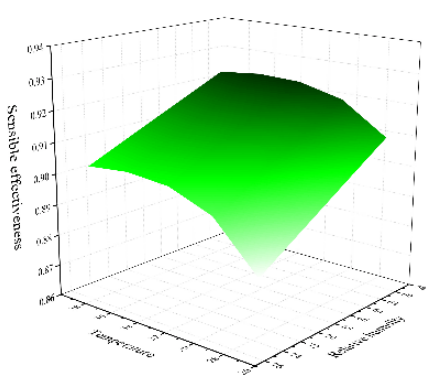

(a)

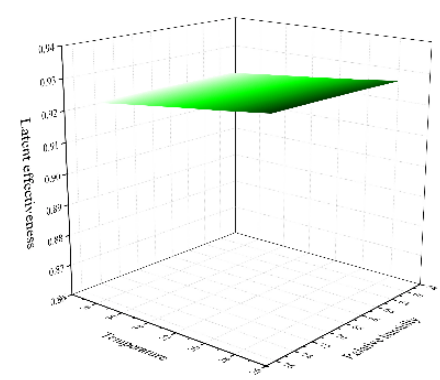

(b)

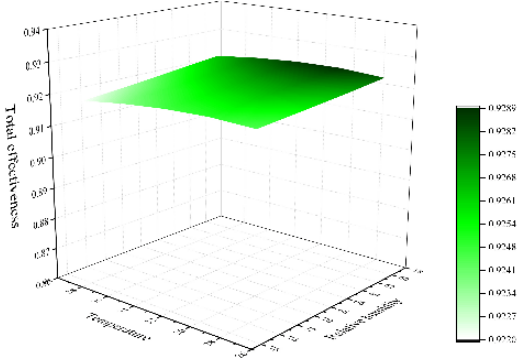

(c)

Fig. 16. Variations of effectiveness: (a) sensible effectiveness; (b) latent effectiveness; (c) total effectiveness with $T_{\text {air,in }}$ and $R H_{\text {air,in }}$. 
601

The maximum sensible effectiveness is 0.924 when $T_{\text {air, in }}=36^{\circ} \mathrm{C}$ and $R H_{\text {air, in }}=60 \%$, while the minimum value is 0.8818 when $T_{\text {air, in }}=27^{\circ} \mathrm{C}$ and $R H_{\text {air, in }}=75 \%$. Comparatively, the latent effectiveness reaches the maximum value of 0.9289 when $T_{\text {air, } i n}=27^{\circ} \mathrm{C}$ and $R H_{\text {air, in }}=$ $75 \%$, while the minimum value is 0.9222 when $T_{\text {air, in }}=39^{\circ} \mathrm{C}$ and $R H_{\text {air, in }}=60 \%$. For the total effectiveness, the maximum value is 0.9249 when $T_{\text {air, in }}=33^{\circ} \mathrm{C}$ and $R H_{\text {air, in }}=60 \%$, while its minimum value is 0.9174 when $T_{\text {air, in }}=39^{\circ} \mathrm{C}$ and $R H_{\text {air }, \text { in }}=75 \%$. Then effects of $T_{a i r, i n}$ and $R H_{a i r, i n}$ on the system performance are discussed separately.

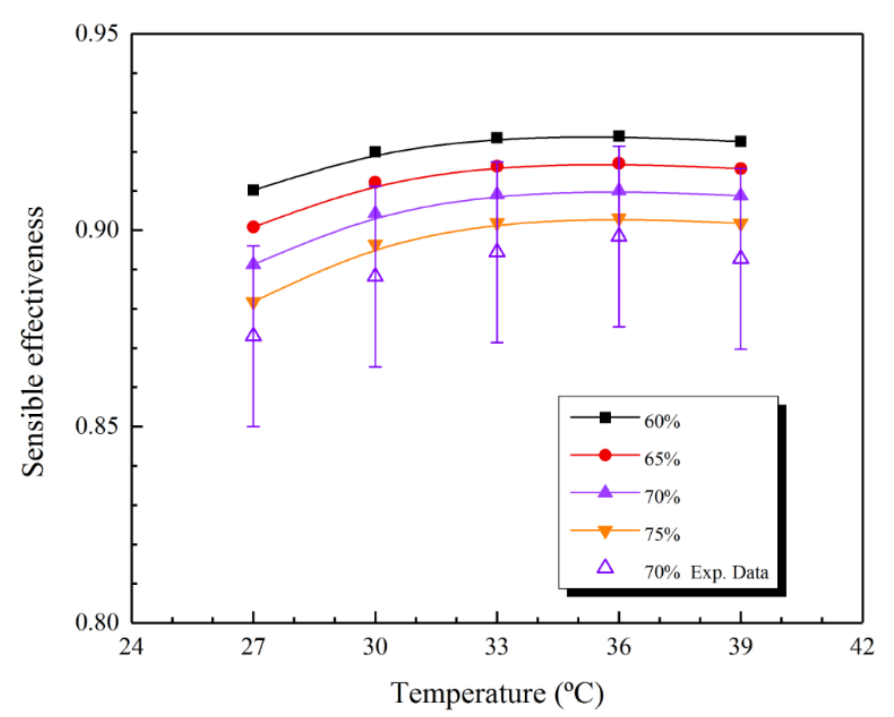

Fig. 17. Sensible effectiveness variations with $T_{\text {air,in }}$ under different $R H_{\text {air,in }}$.

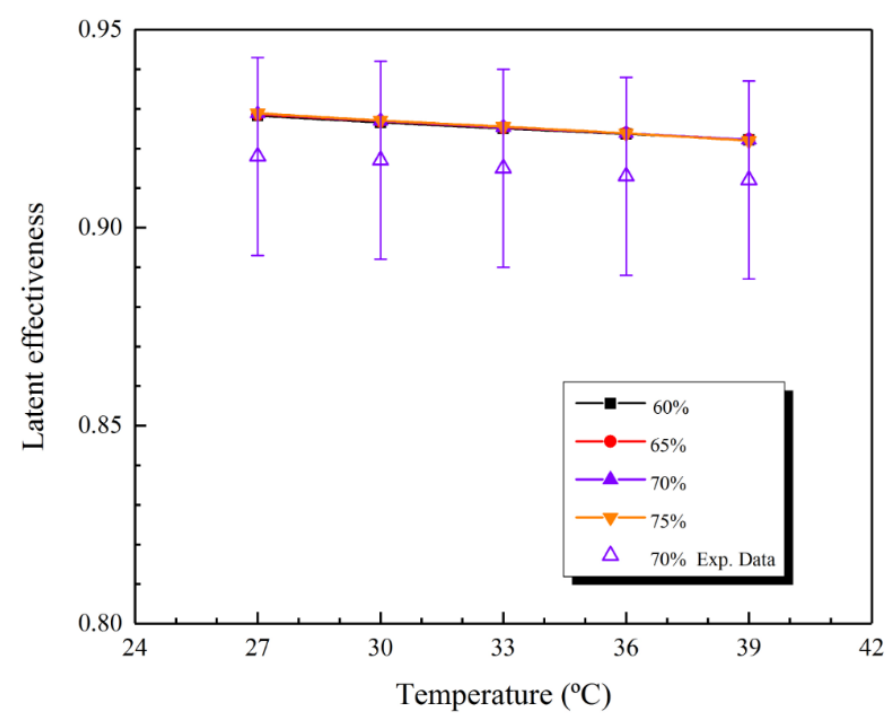

Fig. 18. Latent effectiveness variations with $T_{\text {air, in }}$ under different $R H_{\text {air, in }}$. 


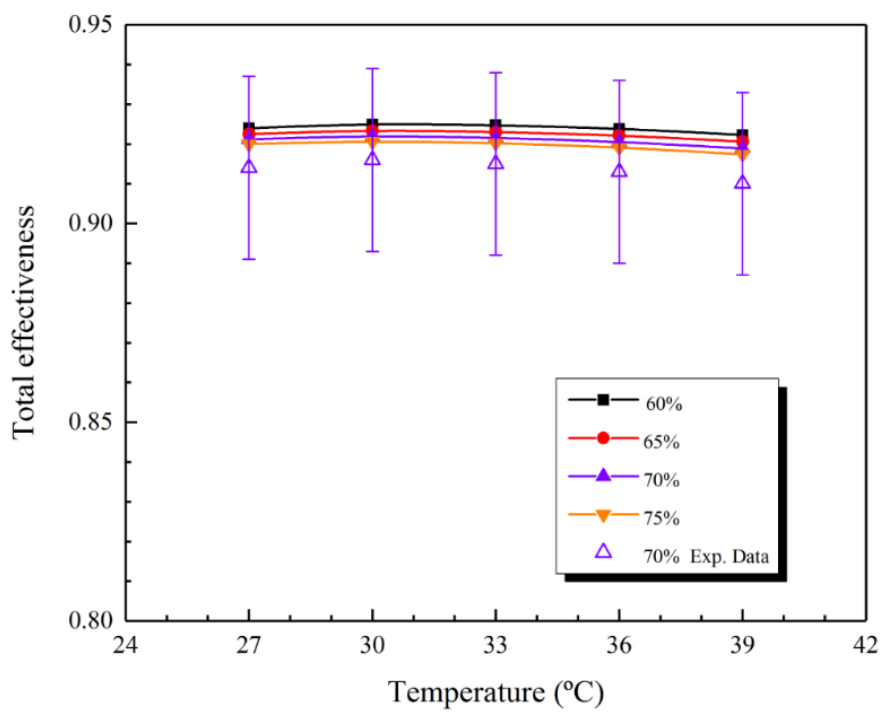

608

609

610

611

612

613

614

615

616

617

618

619

620

621

622

623

624

625

626

627

628

629

630

631

Fig. 19. Total effectiveness variations with $T_{\text {air, in }}$ under different $R H_{\text {air,in }}$.

The effectiveness variations with $T_{\text {air,in }}$ under different $R H_{\text {air, in }}$ are shown in Figs. 17-19, it can be seen that the sensible effectiveness is more sensitive to $T_{\text {air, in }}$ and $R H_{\text {air, in }}$ compared with the latent and total effectiveness. When $T_{\text {air, in }}$ increases from $27^{\circ} \mathrm{C}$ to $36^{\circ} \mathrm{C}$, the sensible effectiveness gradually rises and reaches the peak value at $36^{\circ} \mathrm{C}$. This is because that increasing $T_{\text {air,in }}$ at a constant $R H_{\text {air,in }}$ will enhance the heat transfer potential [16]. However the sensible effectiveness starts to decrease slightly when $T_{a i r, \text { in }}$ is higher than $36^{\circ} \mathrm{C}$. For instance, under $R H_{\text {air }, \text { in }}=75 \%$, the sensible effectiveness rises by $2.42 \%$ (i.e. from 0.8818 to 0.9031 ) when $T_{\text {air,in }}$ increases from $27^{\circ} \mathrm{C}$ to $36^{\circ} \mathrm{C}$. From $36^{\circ} \mathrm{C}$ to $39^{\circ} \mathrm{C}$, the sensible effectiveness decreases slightly (i.e. from 0.9031 to 0.9018 ). For the latent effectiveness, the effect of $T_{\text {air,in }}$ is negligible, for example, under $R H_{\text {air,in }}=75 \%$, the latent effectiveness decreases by $0.74 \%$ (i.e. from 0.9289 to 0.9220 ) when $T_{\text {air, in }}$ rises from $27^{\circ} \mathrm{C}$ to $39^{\circ} \mathrm{C}$. This is attributed to the increased membrane moisture resistance [46]. The case is similar for the total effectiveness, an obvious relationship between the total effectiveness and $T_{\text {air, in }}$ can hardly be found. Effect of $R H_{\text {air,in }}$ on the sensible effectiveness is clear, the lower $R H_{\text {air, in }}$, the higher sensible effectiveness. Furthermore, the improvements of the sensible effectiveness by decreasing $R H_{\text {air,in }}$ at different inlet air temperatures are basically similar. For example, by decreasing $R H_{\text {air }, \text { in }}$ from $75 \%$ to $60 \%$, the sensible effectiveness improvements are $3.22 \%, 2.63 \%, 2.39 \%$, $2.31 \%$ and $2.31 \%$ respectively at $T_{\text {air, in }}$ of $27^{\circ} \mathrm{C}, 30^{\circ} \mathrm{C}, 33^{\circ} \mathrm{C}, 36^{\circ} \mathrm{C}$ and $39^{\circ} \mathrm{C}$. For the latent and total effectiveness, similar to the effects of $T_{\text {air, in }}$, they can barely be affected by $R H_{\text {air,in }}$ as well. In other words, the latent and total effectiveness are insensitive to both $T_{\text {air,in }}$ and $R H_{\text {air }, \text { in }}$ 
In fact, the inlet air state depends on the local weather condition, thus $T_{\text {air, in }}$ and $R H_{\text {air, in }}$ are 633 input parameters for the system rather than controllable ones. Fig. 20 illustrates inlet and outlet 634 air conditions on the psychrometric chart.

635

636

637

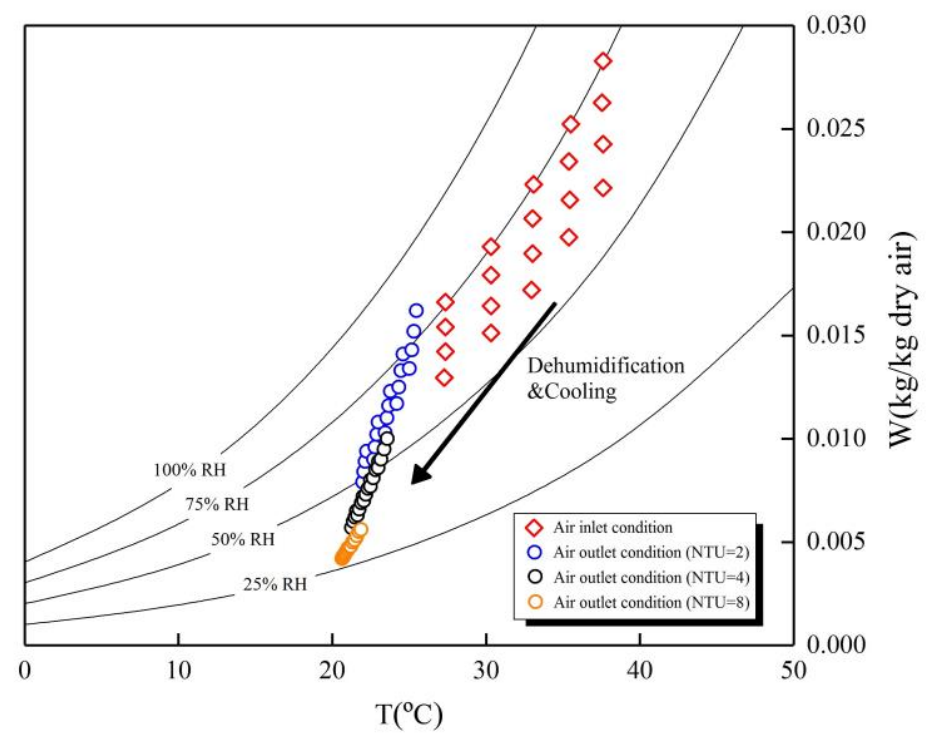

Fig. 20. Inlet and outlet air conditions on the psychrometric chart for numerical modelling.

In traditional cooling coil air-conditioning system, the inlet air is dehumidified by reducing its temperature below its dew point temperature, afterwards the air relative humidity is normally high, which means its temperature is too low for the supply air requirement, and subsequently re-heating is required and more energy is consumed. As seen in Fig. 20, both inlet air temperature and humidity content are reduced after passing through the dehumidifier, and the system outlet air has relatively low temperature and relative humidity. Furthermore, the outlet air is at the very similar condition in spite of different inlet conditions with the same $N T U$, and this is more obvious at high NTU. This means this system has broad adaptability in different weather conditions, and can produce relative stable state supply air.

To sum up, the influences of $T_{\text {air, in }}$ and $R H_{\text {air,in }}$ on the latent and total effectiveness are negligible, while their effects on the sensible effectiveness are weak as well but evident. The cross-flow membrane-based parallel-plate liquid desiccant dehumidification system has better air-conditioning ability to provide the supply air with relatively stable condition despite diverse outdoor conditions. 
A numerical model is developed to investigate the performance of a cross-flow membranebased parallel-plate liquid desiccant dehumidification system, the interaction between the solution and air through membranes is studied by solving heat and mass governing equations in Matlab. The influences of main parameters on dehumidification effectiveness (sensible, latent and total effectiveness) are assessed respectively, which include: number of heat transfer units $(N T U)$, solution to air mass flow rate ratio $\left(m^{*}\right)$, solution temperature $\left(T_{\text {sol }}\right)$, solution concentration $\left(C_{s o l}\right)$, inlet air temperature $\left(T_{\text {air,in }}\right)$ and relative humidity $\left(R H_{\text {air,in }}\right)$. The

665

666 conclusions can be drawn as follows:

- $m^{*}$ and $N T U$ are two of the most important parameters influencing the system effectiveness. Although all effectiveness increase with $m^{*}$ and $N T U$, their increasing gradients hardly change when $m^{*}$ and $N T U$ exceed $m_{c r i t}^{*}$ and $N T U_{\text {crit }}$ respectively.

- It is desirable to operate the system at the critical condition where $m_{c r i t}^{*}$ and $N T U_{c r i t}$ are 1 and 4 respectively in this study.

- Effects of $m^{*}$ and $N T U$ on the system performance are interacted with each other. There is hardly benefit to the system performance improvement by increasing $m^{*}$ at low $N T U$, especially for the latent effectiveness. By contrast, no obvious performance enhancement is achieved by increasing NTU at low $m^{*}$, especially for the sensible effectiveness.

- There is no obvious improvement in the sensible effectiveness with low temperature and high concentration solution, which is insensitive to both $T_{\text {sol }}$ and $C_{s o l}$.

- The latent effectiveness increases significantly with $C_{\text {sol }}$ at a high solution temperature, while the system sensitive effectiveness does not decrease observably.

- The system has broad adaptability in different weather conditions by providing relative stable state supply air, in particular at high NTU.

\section{References}

[1] Perez-Lombard L, Ortiz J, Pout C. A review on buildings energy consumption information, Energy Build. 2008; 40:394 - 398.

[2] Huang SM, Zhang LZ. Researches and trends in membrane-based liquid air dehumidification, Renewable and Sustainable Energy Reviews. 2013; 28:425-440.

[3] Mahmud K, Mahmood GI, Simonson CJ and Besant RW. Performance testing of a counter-cross-flow run-around membrane energy exchanger (RAMEE) system for HVAC applications, Energy Build. 2010; 42(7):1139-1147 
[4] Ge GM, Xiao F, Niu XF. Control strategies for a liquid desiccant air-conditioning system, Energy Build. 2011; 43:1499-1507.

[5] T. Welch, in: H. Carwarardine, K. Butcher (Eds.), CIBSE Knowledge Series: KS13Refrigeration, CIBSE Publications, London, UK, 2008.

[6] Das RS, Jain S. Performance characteristics of cross-flow membrane contractors for liquid desiccant systems, Applied Energy. 2015; 141:1-11.

[7] The CIBSE Journal CPD Programme: liquid desiccant for dehumidification in building air conditioning systems.

[8] Dai YJ, Wang RZ, Zhang HF, Yu JD. Use of liquid cooling to improve the performance of vapor compression air conditioning, Applied Thermal Engineering. 2001; 21:11851202.

[9] Liu XH, Geng KC, Lin BR, Jiang Y. Combined cogeneration and liquid desiccant system applied in a demonstration building, Energy Build. 2004; 36:945-953.

[10] Kinsara AA, Elsayed MM, Al-Rabghi OM. Proposed energy-efficient air conditioning system using liquid desiccant, Applied Thermal Engineering. 1996; 16(10):791-806.

[11] Katejanekarn T, Kumar S. Performance of a solar-regenerated liquid desiccant ventilation pre-conditioning system, Energy Build. 2008; 40:1252-1267.

[12] Moghaddam DG, Oghabi A, Ge GM, Besant RW, Simonson CJ. Numerical model of a small-scale liquid-to-air membrane energy exchanger: Parametric study of membrane resistance and air side convective heat transfer coefficient, Applied Thermal Engineering. 2013; 61; 245-258.

[13] Moghaddam DG, Le Poudre P, Besant RW, Simonson CJ. Steady-state performance of a small-scale liquid-to-air membrane energy exchanger for different heat and mass transfer directions, and liquid desiccant types and concentrations: experimental and numerical data, ASMEJ Heat Transfer. 2013; 135:1-13.

[14] Moghaddam DG, Besant RW, Simonson CJ. Solution-side effectiveness for a liquidto-air membrane energy exchanger used as a dehumidifier/regenerator, Applied Energy. 2014; 113:872-882.

[15] Moghaddam DG, LePoudre P, Ge GM et al. Small-scale single-panel liquid-to-air membrane energy exchanger (LAMEE) test facility development, commissioning and evaluating the steay-state performance, Energy and Buildings. 2013; 66:424-436.

[16] Abdel-Salam AH, Ge GM, Simonson CJ. Performance analysis of a membrane liquid desiccant air-conditioning system, Energy and Buildings. 2013; 62:559-569.

[17] Vali A, Ge GM, Besant RW, Simonson CJ. Numerical modelling of fluid flow and coupled heat and mass transfer in a counter-cross-flow parallel-plate liquid-to-air membrane energy exchanger, Int J Heat Mass Transfer. 2015; 89:1258-1276. 
[18] Huang SM, Yang ML, Yang XX. Performance analysis of a quasi-counter flow parallel-plate membrane contractor used for liquid desiccant air dehumidification, Applied Thermal Engineering. 2014; 63:323-332.

[19] Huang SM, Zhong ZR, Yang ML. Conjugate heat and mass transfer in an internallycooled membrane-based liquid desiccant dehumidifier (IMLDD), Journal of Membrane Science. 2016; 508:73-83.

[20] Huang SM, Qiu D, Huang WH, Yang ML, Xiao HM. Laminar flow and heat transfer in a quasi-counter flow parallel-plate membrane channel in the solution side with cooling tubes, Int J Heat Mass Transfer. 2017; 105:769-780.

[21] Zhang LZ, Huang SM, Pei LX. Conjugate heat and mass transfer in a cross-flow hollow fiber membrane contractor for liquid desiccant air dehumidification, Int J Heat Mass Transfer. 2013; 55(25-26):8061-72.

[22] Zhang LZ, Huang SM, Zhang WB. Turbulent heat and mass transfer across a hollow fiber membrane bundle considering interactions between neighbouring fibers, Int $\mathbf{J}$ Heat Mass Transfer. 2013; 64:162-72.

[23] Ouyang Y, Li ZX, Zhang LZ. Oblique fluid flow and heat transfer across a hollow fiber membrane bank under uniform temperature conditions, Journal of Membrane Science. 2014; 470:524:534.

[24] Ouyang Y, Zhang LZ. Conjugate heat and mass transfer in a skewed flow hollow fiber membrane bank used for liquid desiccant air dehumidification, Int $\mathbf{J}$ Heat Mass Transfer. 2016; 93:23-40.

[25] Huang SM, Qin GF, Yang ML, Yang XX, Zhong WF. Heat and mass transfer deteriorations in an elliptical hollow fiber membrane tube bank for liquid desiccant air humidification, Applied Thermal Engineering. 2013; 57:90-98.

[26] Huang SM, Yang ML. Heat and mass transfer enhancement in a cross-flow elliptical hollow fiber membrane contractor used for liquid desiccant air dehumidification, Journal of Membrane Science. 2014; 449:184-192.

[27] Li GP, Zhang LZ. Investigation of a solar energy driven and hollow fiber membranebased humidification-dehumidification desalination system, Applied Energy. 2016; 177:393-408.

[28] Zhang N, Yin SY, Zhang LZ. Performance study of a heat pump driven and hollow fiber membrane-based two-stage liquid desiccant air dehumidification system, Applied Energy. 2016; 179:727-737.

[29] Labban O, Chen TY, Ghoniem AF, Lienhard V JH, Norford LK. Next-generation HVAC: Prospects for and limitations of desiccant and membrane-based dehumidification and cooling, Applied Energy. 2017; 200:330-346. 
[30] Bai HY, Zhu J, Chen ZW, et al. Performance testing of a cross-flow membrane-based liquid desiccant dehumidification system, Applied Thermal Engineering. 2017; 119:119-131.

[31] Huang SM, Zhang LZ, Tang K, Pei LX. Fluid and heat mass transfer in membrane parallel parallel-plates channels used for liquid desiccant air dehumidification. Int $\mathbf{J}$ Heat Mass Transfer 2012; 55:2571-80.

[32] Huang SM, Zhang LZ, Yang M. Conjugate heat and mass transfer in membrane parallel-plates ducts for liquid desiccant air dehumidification: effects of the developing entrances, J Membrane Science. 2013; 437:82-9.

[33] Seyed-Ahmadi M, Erb B, Simonson CJ, Besant RW. Transient behaviour of runaround heat and moisture exchanger system; part I: model formulation and verification, Int J Heat Mass Transfer. 2009; 52: 6000-11.

[34] Vali A, Simonson CJ, Besant RW, Mahmood G. Numerical model and effectiveness correlations for a run-around heat recovery system with combined counter and cross flow exchangers, Int J Heat Mass Transfer. 2009; 52:5827-40.

[35] Mander P (2012) How to convert relative humidity to absolute humidity available at <https://carnotcycle.wordpress.com/2012/08/04/ how-to-convert-relative-humidity-toabsolute-humidity/>.

[36] ASHRAE, 2013 ASHRAE Handbook Fundamentals. Atlantal 2013.

[37] Cisternas LA and Lam EJ. An analytic correlation for the vapour pressure of aqueous and non-aqueous solutions of single and mixed electrolytes. Part II. Application and extension, Fluid Phase Equilib. 1991; 62:11-27.

[38] ANSI/ASHRAE STANDARD 84-2013, Method of test for air-to-air heat/energy exchangers, American society of heating, refrigerating, and air-conditioning engineers, Atlanta.

[39] Simonson CJ, Besant RW. Energy wheel effectiveness: Part 1 - Development of dimensionless groups, Int J Heat Mass Transfer. 1999; 42:2161-70.

[40] Taylor JR. An Introduction to Error Analysis: The Study of Uncertainties in Physical Measurements, second ed., University Science Books, Sausalito, CA, 1997.

[41] Shah RK, Sekulic DP. Fundamental of Heat Exchanger Design, John Wiley \& Sons, Hoboken, NJ, 2003, 97-164.

[42] Zhang LZ, Niu JL. Effectiveness correlations for heat and moisture transfer processes in an enthalpy exchanger with membrane cores, Journal of Heat Transfer. 2002; 10:124.

[43] Fan H. Modelling a run-around heat and moisture recovery system. (M.Sc. thesis). Saskatoon, Saskatchewan, Canada: Department of Mechanical Engineering, College of Engineering, University of Saskatchewan; 2005. 
800

801

802

803

804

805

806

807

808

809

[44] Fan H, Simonson CJ, Besant RW, Shang W. Performance of a run-around system for HVAC heat and moisture transfer applications using cross-flow plate exchangers coupled with aqueous lithium bromide, HVAC \& R Res 2006; 12:313-36.

[45] Namvar R, Pyra D, Ge GM, Simonson CJ. Transient characteristics of a liquid-to-air membrane energy exchanger (LAMEE) experimental data with correlations, Int J Heat Mass Transfer. 2012; 55:6682-6694.

[46] Niu JL, Zhang LZ. Membrane-based enthalpy exchanger: material considerations and clarification of moisture resistance, Journal of Membrane Science. 2001; 189(2):179191. 